\title{
A Lagrangian perspective on stable water isotopes during the West African Monsoon
}

\author{
Christopher J. Diekmann ${ }^{1}$, Matthias Schneider ${ }^{1}$, Peter Knippertz ${ }^{1}$, Andries J. \\ de Vries ${ }^{3}$, Stephan Pfahl ${ }^{4}$, Franziska Aemisegger ${ }^{3}$, Fabienne Dahinden $^{3}$, \\ Benjamin Ertl ${ }^{1,2}$, Farahnaz Khosrawi $^{1}$, Heini Wernli ${ }^{3}$, Peter Braesicke $^{1}$ \\ ${ }^{1}$ Institute for Meteorology and Climate Research, Karlsruhe Institute of Technology, Karlsruhe, Germany \\ ${ }^{2}$ Steinbuch Centre for Computing, Karlsruhe Institute of Technology, Karlsruhe, Germany \\ ${ }^{3}$ Institute for Atmospheric and Climate Science, ETH Zurich, Zurich, Switzerland \\ ${ }^{4}$ Institute of Meteorology, Freie Universität Berlin, Berlin, Germany
}

Key Points:

- New Lagrangian framework to attribute variability in $\left\{\mathrm{H}_{2} \mathrm{O}, \delta \mathrm{D}\right\}$ distributions to air mass mixing and phase changes of water.

- Application to West African Monsoon season 2016 shows characteristic mixing and precipitation effects along trajectories.

- New framework can be used for the interpretation of satellite and in-situ observations, and for model validation in future work. 


\section{Abstract}

We present a Lagrangian framework for identifying mechanisms that control the isotopic composition of mid-tropospheric water vapor in the Sahel region during the West African Monsoon 2016. In this region mixing between contrasting air masses, strong convective activity, as well as surface and rain evaporation lead to high variability in the distribution of stable water isotopologues. Using backward trajectories based on high-resolution isotope-enabled model data, we obtain information not only about the source regions of Sahelian air masses, but also about the evolution of $\mathrm{H}_{2} \mathrm{O}$ and its isotopologue HDO (expressed as $\delta \mathrm{D})$ along the pathways of individual air parcels. We sort the full trajectory ensemble into groups with similar transport pathways and hydro-meteorological properties, such as precipitation and relative humidity, and investigate the evolution of the corresponding paired $\left\{\mathrm{H}_{2} \mathrm{O}, \delta \mathrm{D}\right\}$ distributions. The use of idealized process curves in the $\left\{\mathrm{H}_{2} \mathrm{O}, \delta \mathrm{D}\right\}$ phase space allows us to attribute isotopic changes to contributions from (1) air mass mixing, (2) Rayleigh condensation during convection, and (3) microphysical processes depleting the vapor beyond the Rayleigh prediction, i.e., partial rain evaporation in unsaturated and isotopic equilibration in saturated conditions. Different combinations of these processes along the trajectory ensembles are found to determine the final isotopic composition in the Sahelian troposphere during the monsoon.

The presented Lagrangian framework is a powerful tool for interpreting tropospheric water vapor distributions. In the future, it will be applied to satellite observations of $\left\{\mathrm{H}_{2} \mathrm{O}\right.$, $\delta \mathrm{D}\}$ over Africa and other regions in order to better quantify characteristics of the hydrological cycle.

\section{Introduction}

The meteorology and hydrology of West Africa is dominated by the complex West African Monsoon (WAM) system (Fink et al., 2017). The onset of the WAM is characterized by a shift of maximum rainfall from the Guinea Coast to the Sahel (Sultan \& Janicot, 2003; Fitzpatrick et al., 2015), where the rainfall is crucial for the livelihoods of the local population in terms of water resources. During the Sahelian rainy season from July to September, the moist southwesterly monsoon flow from the tropical Atlantic encounters the dry northeasterly Harmattan winds along the so-called Intertropical Discontinuity (ITD), a sharp air mass boundary characterized by large contrasts in humidity, temperature, vertical stability, and dust content. The temperature difference leads to a marked 
thermal wind maximum at around $600 \mathrm{hPa}$ and $15^{\circ} \mathrm{N}$, the African easterly jet (AEJ) (Cook, 1999; Wu et al., 2009). Large-scale subsidence and occasional extratropical mid-level dry intrusions from northern Africa (Roca et al., 2005) enhance the dryness on the poleward side of the ITD. In the environment of the ITD, strong convective instability and vertical wind shear support the development of highly organized, long-lived Mesoscale Convective Systems (MCSs; Fink \& Reiner, 2003). When the mid-level dry air overrides the low-level moist monsoonal air, strong downdrafts and rain evaporation occur, which favour the formation of surface cold pools and ultimately result in intense air mass mixing.

The complex interactions of large-scale dynamical with small-scale convective and microphysical processes lead to a substantial spatio-temporal variability in the tropospheric moisture budget over the Sahel, which is still poorly understood (Bielli et al., 2010; Meynadier, Bock, Guichard, et al., 2010; Meynadier, Bock, Gervois, et al., 2010). The lack of a dense operational measurement network further hampers a detailed analysis of Sahelian moisture and its sources (Parker et al., 2008). Consistent with this, both weather forecasts (Vogel et al., 2018) and climate projections (Roehrig et al., 2013) show large uncertainties over the Sahel. Through teleconnections (e.g., Bielli et al., 2010), the poor performance of numerical models over West Africa can even negatively affect forecasts over the adjacent Atlantic and Europe (Pante \& Knippertz, 2019). Given the enormous socio-economic importance of Sahelian rainfall, new approaches to better understand and quantify moisture processes in this region are urgently needed.

During the last decades, the analysis of stable water isotopologues in atmospheric water vapor and precipitation has been established as a powerful tool for investigating atmospheric moisture pathways. As each water isotopologue (hereafter referred to as water isotope) is associated with characteristic water vapor pressures and diffusivities, the ratios of different isotopes are altered during phase changes. The ratio $R$ between the heavier water isotope $\mathrm{HDO}$ against the lighter $\mathrm{H}_{2} \mathrm{O}$ is given as $\delta \mathrm{D}=1000 \times\left(R / R_{s}-\right.$ 1) in \%o, with $R_{s}=3.1152 \times 10^{-4}$ (Vienna Standard Mean Ocean Water; Craig, 1961). Several studies have emphasized the potential of the paired analysis of $\mathrm{H}_{2} \mathrm{O}$ and $\delta \mathrm{D}$, as this allows for evaluating effects of different moisture processes on tropospheric water vapor, such as air mass mixing (Noone et al., 2011; González et al., 2016; Lacour et al., 2017), condensation (Noone, 2012; Schneider et al., 2016), rain evaporation (Worden et al., 2007; Field et al., 2010), and deep convection (Bolot et al., 2013; Lacour et al., 2018). In this context, Noone (2012) derived a theoretical framework for characterizing the vari- 
ability between $\mathrm{H}_{2} \mathrm{O}$ and $\delta \mathrm{D}$ by means of idealized process curves in the $\left\{\mathrm{H}_{2} \mathrm{O}, \delta \mathrm{D}\right\}$ phase space that describe effects of mixing (Keeling, 1958; Gedzelman, 1988), and cloud and rain microphysics (Rayleigh, 1902; Dansgaard, 1964; Merlivat \& Jouzel, 1979; Ciais \& Jouzel, 1994). Even though some of these simple models (e.g. the Rayleigh distillation for cloud formation) implicitly involve the Lagrangian perspective, the theoretical framework of Noone (2012) has never been explicitly applied in combination with air parcel trajectories and their isotope signals.

So far only few studies have investigated tropospheric distributions of stable water isotopes during the WAM. For instance, by using local rainfall samples and laser-based water vapor measurements, the impact of monsoon convection on isotope abundances was analyzed (Risi, Bony, Vimeux, Descroix, et al., 2008; Risi, Bony, Vimeux, Chongd, \& Descroixe, 2010; Tremoy et al., 2012, 2014). A model-based approach to understand the Sahelian water budget was conducted by Risi, Bony, Vimeux, Frankenberg, et al. (2010), who underlined the strong influence of large-scale subsidence and convective activity to the isotopic variability in vapor and rain over the Sahel. However, this study concluded that the quantification of convective processes still remains a key challenge.

Recently, a novel dataset of paired distributions of mid-tropospheric $\mathrm{H}_{2} \mathrm{O}$ and $\delta \mathrm{D}$ (also referred to as $\left\{\mathrm{H}_{2} \mathrm{O}, \delta \mathrm{D}\right\}$ pairs) was generated by using remote sensing data from the satellite sensor Metop/IASI (Diekmann et al., 2021; Schneider et al., 2021). Due to its high resolution in space (horizontal pixel size of $12 \mathrm{~km}$, sensitive to $\delta \mathrm{D}$ variations between $2-7 \mathrm{~km}$ ) and time (global coverage of cloud-free scenes twice per day, between October 2014 to June 2019), this dataset provides promising new opportunities for investigating the isotopic composition in the mid-troposphere, globally and in regions of particular interest such as West Africa. However, the challenge to take full benefit of this new wealth of information lies in the fact that individual scenes give snapshot distributions of the current atmospheric state without direct information on the processes that have led to the measured composition, particularly as different combinations of processes can lead to similar distributions in $\left\{\mathrm{H}_{2} \mathrm{O}, \delta \mathrm{D}\right\}$.

To overcome this challenge and aid the interpretation of Metop/IASI or similar data, we here develop a new Lagrangian framework for attributing signals in paired $\left\{\mathrm{H}_{2} \mathrm{O}, \delta \mathrm{D}\right\}$ distributions to underlying processes. For this purpose, we analyze the evolution of meteorological conditions, including isotope variables, along the atmospheric pathways of 
backward trajectories in order to understand the physical causes of air mass characteristics found in selected target regions.

As an exemplary case study to demonstrate the power of our new framework, we have selected the WAM period of 2016, for which the DACCIWA (Dynamics-AerosolChemistry-Cloud Interactions in West Africa) measurement campaign elaborated an extensive meteorological documentation (Knippertz et al., 2017). As basis for the trajectory calculation we use the regional isotope-enabled model $\mathrm{COSMO}_{\text {iso }}$ (see Sect. 3.1) that was run in a convection-permitting setup in order to account for the complex meteorology of the region (e.g. Pante \& Knippertz, 2019). Using the COSMO iso $_{\text {output, we ap- }}$ ply the Lagrangian analysis tool LAGRANTO (see Sect. 3.2) to compute 7-day backward trajectories from the Sahelian mid-troposphere and to trace moisture diagnostics along individual trajectories. This paves the way for categorizing the temporal evolution of the $\left\{\mathrm{H}_{2} \mathrm{O}, \delta \mathrm{D}\right\}$ signals along the trajectories based on the underlying meteorological conditions. In this manner, we can examine, whether and under which conditions the theoretical process curves of mixing and microphysical processes from Noone (2012) are representative for the isotopic evolution along the trajectories, and to which extent they can explain the general isotopic evolution in the Sahelian mid-troposphere during the monsoon season 2016.

In Sect. 2, we give a short overview about idealized process signals in paired $\left\{\mathrm{H}_{2} \mathrm{O}\right.$, $\delta \mathrm{D}\}$ distributions. Section 3 describes our modelling approach based on $\mathrm{COSMO}_{\text {iso }}$, LAGRANTO, and the applied process-attribution method. In Sect. 4, we analyze the isotopic composition of the Sahelian troposphere during the WAM season 2016. Finally, Sect. 5 wraps up the results and gives an outlook on future work.

\section{Signature of different moist processes in $\left\{\mathrm{H}_{2} \mathrm{O}, \delta \mathrm{D}_{v}\right\}$ pair distribu- tions}

Throughout the last decades, the paired analysis of stable water isotopes has proven highly valuable for retrieving information about atmospheric moisture processes (e.g. Worden et al., 2007; Noone et al., 2011; Schneider et al., 2016; Eckstein et al., 2018; Graf et al., 2019). As a theoretical basis for interpreting paired distributions of $\mathrm{H}_{2} \mathrm{O}$ (given in volume mixing ratios) and $\delta \mathrm{D}$ in water vapor, Noone (2012) compiled a set of idealized process curves to describe how different tropospheric moisture processes are reflected in the $\left\{\mathrm{H}_{2} \mathrm{O}, \delta \mathrm{D}\right\}$ phase space. In our work, we concentrate on the process curves that gov- 

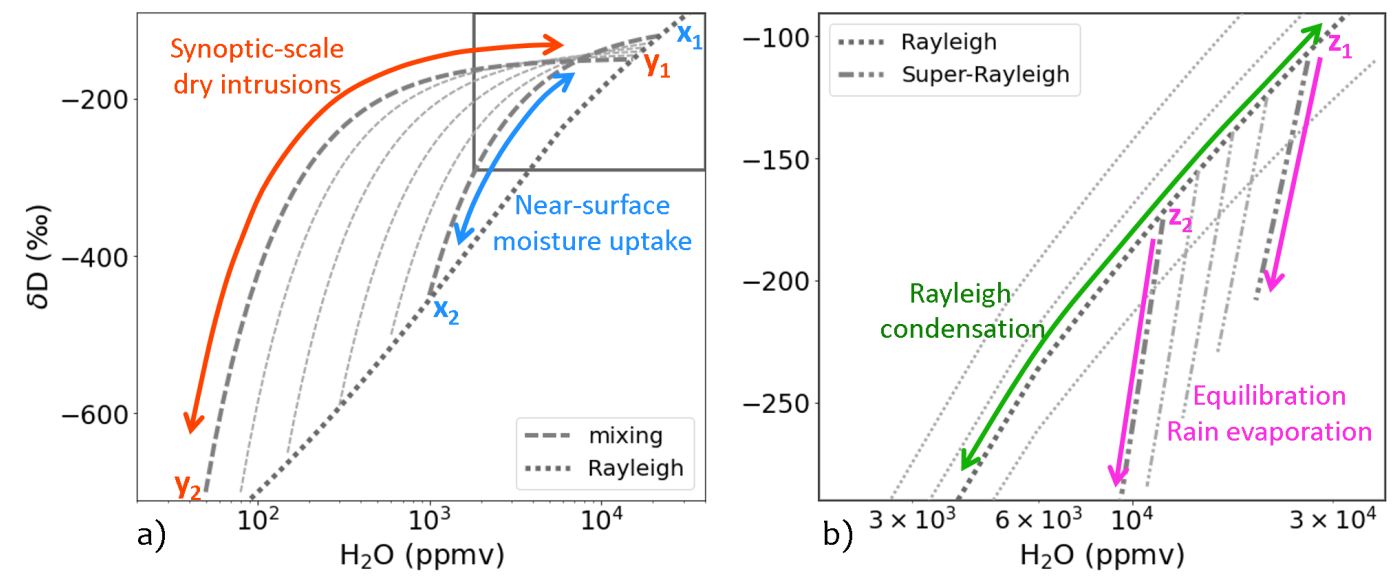

Figure 1. Overview of idealized process curves for paired distributions of $\mathrm{H}_{2} \mathrm{O}$ and $\delta \mathrm{D}_{v}$ according to Noone (2012). The colored arrows indicate process curves that are found to represent the isotopic composition of the Sahelian troposphere during the WAM season 2016. (a) Effects of air mass mixing, where the blue (orange) curve indicates mixing between the end members $x_{1}$ and $x_{2}\left(y_{1}\right.$ and $\left.y_{2}\right)$. (b) Effects of microphysical processes, where the green line marks a Rayleigh process with initial conditions of $T_{0}=30^{\circ} \mathrm{C}, R H_{0}=90 \%$, and $\delta \mathrm{D}_{v, 0}=-80 \%$ and the magenta lines Super-Rayleigh signals starting at two different positions of the Rayleigh line $\left(z_{1}\right.$ and $\left.z_{2}\right)$. Note that (b) only shows a subset of (a) marked by the black box in the top right corner of (a).

ern the isotopic variability in the Sahelian troposphere during the West African Monsoon, as summarized in Fig. 1. This section provides the theoretical background for the individual process curves, for which model-based evidence will be given in the course of this study.

First, let's assume that two air parcels with the specific moisture contents $q_{v 0}$ and $q_{v 1}$ and the isotopic compositions $\delta \mathrm{D}_{v 0}$ and $\delta \mathrm{D}_{v 1}$ mix without fractionation (i.e., no phase changes during the mixing). The mixed moisture composition $q_{v}$ and $\delta \mathrm{D}_{v}$ then result as follows:

$$
\begin{gathered}
q_{v}=f q_{v 0}+(f-1) q_{v 1} \\
\delta D_{v}=\frac{f q_{v 0} \delta D_{v 0}+(f-1) q_{v 1} \delta D_{v 1}}{q_{v}}
\end{gathered}
$$

with $f$ indicating the relative contribution of the two air masses (Noone et al., 2011).

Note that we use the subscript $v$ for the vapor phase and $c$ for the condensate throughout the paper. Later, we will distinguish between different categories of condensate, namely rain $(r)$, snow $(s)$, liquid $(l)$ and ice $(i)$ clouds. While $q_{v}$ exhibits linear mixing, $\delta \mathrm{D}_{v}$ fol- 
lows a hyperbolic curve, as the ratio between light and heavy isotopes is dominated by the moister air mass (Noone, 2012). The position of the hyperbolic curve in the $\left\{\mathrm{H}_{2} \mathrm{O}\right.$, $\left.\delta \mathrm{D}_{v}\right\}$ diagram is determined by the isotopic composition of the moist and dry end members. For instance, Fig. 1a shows the mixing curves for a dry mixing process, where the dry end member is located at very low $\mathrm{H}_{2} \mathrm{O}$ and $\delta \mathrm{D}_{v}$ (orange curve), and for a moist mixing process with both end members $\left(x_{1}\right.$ and $\left.x_{2}\right)$ being relatively moist (blue curve). The dry mixing curve is representative for air masses that originate from dry regions of the upper troposphere (mixing member $y_{2}$ ) and become more humid while they are subsiding into lower altitudes (mixing member $y_{1}$ ), whereas the moist mixing curve illustrates a near-surface moistening due to surface evaporation (see Sect. 4.2 and 4.4.1).

Second, if microphysical processes induce a phase change of atmospheric water, fractionation between $\mathrm{H}_{2} \mathrm{O}$ and $\mathrm{HDO}$ occurs. Since the HDO molecule has higher binding energies in the condensed phase than $\mathrm{H}_{2} \mathrm{O}$, the two isotopes have different water vapor pressures leading to equilibrium fractionation (Urey, 1947; Bigeleisen, 1961). Additionally, differences in molecular mass leads to non-equilibrium fractionation due to differing diffusivities. The former refers to a reversible isotope separation under thermodynamic equilibrium between a condensate (isotopic ratio $R_{c}$ ) and the ambient vapor (isotopic ratio $R_{v}$ ) according to the fractionation factor:

$$
\alpha_{e q, c}=\frac{R_{c}}{R_{v}}
$$

The values for $\alpha_{e q, c}$ vary with temperature as also the saturation vapor pressure does. They were determined for liquid and ice condensation during various laboratory studies (e.g. Merlivat \& Nief, 1967; Majoube, 1971; Horita \& Wesolowski, 1994). Non-equilibrium fractionation is assumed to occur in addition to equilibrium fractionation for processes that enforce a fast isotope flux between vapor and liquid, for instance when ventilated or unsaturated conditions prevail.

A simple framework for the isotopic fractionation in a precipitating air parcel is the Rayleigh distillation process (Rayleigh, 1902; Dansgaard, 1964). In this model, a moist adiabatic ascent is assumed with immediate removal of the condensate (Johnson et al., 2001). As soon as the dew point temperature is reached, condensation begins and condensate forms from ambient vapor under equilibrium conditions. While this process enriches the condensate with heavy isotopes, the ambient vapor gets depleted according 
to

$$
\ln \left(\frac{R_{v}}{R_{v 0}}\right)=\left(\alpha_{e q}-1\right) \ln \left(\frac{q_{v}}{q_{v 0}}\right)
$$

The conditions at the starting point of the ascent are defined by $q_{v 0}$ and the isotopic ratio $R_{v 0}$. For condensation above the frost point (263 K, according to Noone (2012) and Ciais and Jouzel (1994)) the liquid fractionation factor (3) is used and at colder temperatures, the factor over ice is applied. A typical Rayleigh line for convective condensation over West Africa is shown in green in Fig. 1b (see Sect. 4.2 and 4.4.2).

If a liquid hydrometeor falls into unsaturated air, evaporation takes place and acts as a reversed distillation process (Bony et al., 2008). During partial evaporation of rainfall lighter isotopes evaporate preferentially (Lee \& Fung, 2008; Risi, Bony, \& Vimeux, 2008; Noone, 2012). While enriching the rain water, the ambient vapor content increases due to the input of relatively more depleted evaporated rainfall water. In the $\left\{\mathrm{H}_{2} \mathrm{O}, \delta \mathrm{D}_{v}\right\}$ space this leads to a drop below the Rayleigh curve (Dansgaard, 1964; Rozanski et al., 1992) and creates a so-called Super-Rayleigh signal, representing a Rayleigh process with an increased fractionation factor (Noone, 2012):

$$
\alpha>\alpha_{e q}
$$

Starting at different positions of the Rayleigh curve, this creates signals indicated by magenta lines in Fig. 1b. As will be shown in Sect. 4.2 and 4.4.3, these curves correspond to rain evaporation in mid-levels $(4-6 \mathrm{~km})$ and near-surface sub-cloud areas $(0-1.5 \mathrm{~km})$.

In saturated conditions $(R H=100 \%)$, equilibrium exchange of water molecules between vapor and liquid may affect their isotopic compositions, because saturation does not necessarily imply that an equilibrium between liquid and vapor is reached immediately for HDO as well. Particularly in the case of a fast process such as during the fall of a droplet, the isotope composition of the vapor can be altered by equilibrium exchange with the falling droplet. If an isotopic disequilibrium between the ambient air $\left(\delta \mathrm{D}_{v}\right)$ and the rain drop $\left(\delta \mathrm{D}_{r}\right)$ exists, an HDO flux works towards equilibrating both phases (Stewart, 1975; Lawrence et al., 2004). For instance, if rain drops with low $\delta$ D fall through saturated areas with a relatively more enriched vapor, a net isotopic flux from the vapor to the condensate occurs, while $q_{v}$ remains constant. This leads to a lowering of $\delta \mathrm{D}_{v}$ at constant $q_{v}$. A mathematical demonstration of the depleting effect of isotopic equilibration on $\delta \mathrm{D}_{v}$ due to the interaction with more depleted rain drops is given in Appendix A. Throughout this study we show that thereby $\left\{\mathrm{H}_{2} \mathrm{O}, \delta \mathrm{D}_{v}\right\}$ signals develop that lie be- 


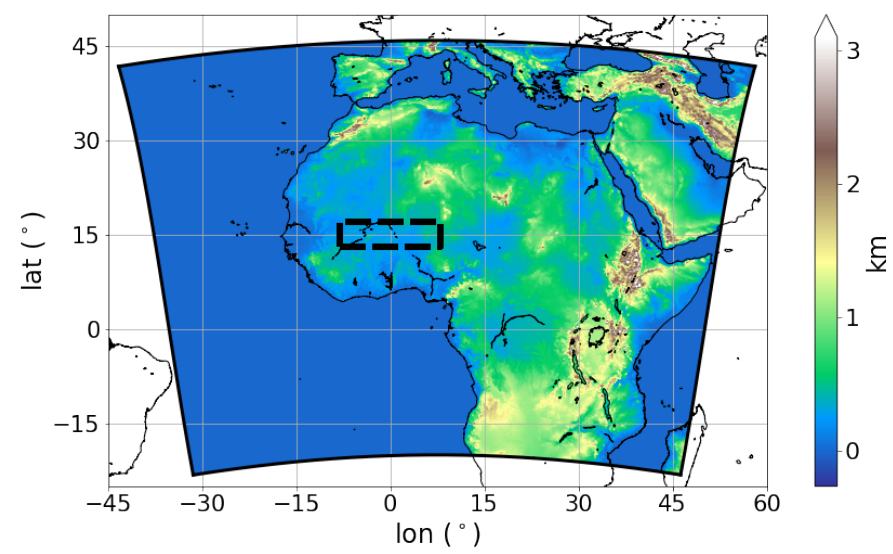

Figure 2. The black-framed colored box indicates the model domain used for the simulation with $\mathrm{COSMO}_{\text {iso. The colors show the topography as considered in the COSMO }}$ iso simulation. The black dashed box frames the target region over the Sahel, which was used to initialize the backward trajectories.

low the Rayleigh curve and correlate with the Super-Rayleigh curves computed for partial evaporation according to (Noone, 2012) (see magenta lines in Fig. 1 and discussions in Sect. 4.4.3).

The disequilibrium between rain and vapor can be approximated as follows (e.g. Tremoy et al., 2014; Aemisegger et al., 2015; Graf et al., 2019):

$$
\delta D_{v, d e q}=\delta D_{v}-\delta D_{v, e q}=\delta D_{v}-\left[\alpha_{e q}\left(\delta D_{r}+1000\right)-1000\right]
$$

$\delta D_{v, e q}$ is the isotopic composition that the vapor would have if it were in isotopic equilibrium with the rain drop (subscript $r$ stands for rain). In a saturated and equilibrated state, $\delta \mathrm{D}_{v, d e q}$ tends towards $0 \%$, whereas partial rain evaporation (both equilibrium and non-equilibrium fractionation) generates a negative disequilibrium.

\section{Data and Methods}

In this section, we introduce the model data and trajectory tool that we use to calculate the backward trajectories for the Sahelian mid-troposphere during the WAM season 2016, and explain the process-attribution strategy. 


\subsection{The isotope-enabled model $\mathrm{COSMO}_{\text {iso }}$}

$\mathrm{COSMO}_{\text {iso }}$ is the isotope-enabled version of the non-hydrostatic limited-area weather and climate model COSMO (Steppeler et al., 2003) and is documented in detail in Pfahl et al. (2012). As a regional model that is fed by boundary data from a global model, it efficiently enables simulations with high spatio-temporal resolutions at convective-resolving scales. It incorporates the fractionating processes of $\mathrm{HDO}$ and $\mathrm{H}_{2}^{18} \mathrm{O}$ within its whole hydrological cycle (Pfahl et al., 2012). Fractionation is assumed whenever phase changes occur that involve the vapor phase. A one-moment microphysical scheme is used and the isotopic composition is calculated for water vapor, liquid and ice clouds as well as rain and snow. For this purpose, it includes the fractionation schemes of Stewart (1975) for rain evaporation and Jouzel and Merlivat (1984) for snow formation. Further, it uses the isotope-enabled multi-layer soil moisture scheme TERRA $A_{\text {iso }}$ for fractionating soil evaporation and non-fractionating plant transpiration (Christner et al., 2018). Fractionation during ocean evaporation is represented by the Craig-Gordon-model (Craig \& Gordon, $1965)$.

Here we use data from a $\mathrm{COSMO}_{\text {iso }}$ simulation with a focus on West Africa during the WAM season 2016. The simulation period is chosen to match the DACCIWA campaign (01 June - 31 July 2016, Knippertz et al., 2017) and the model output frequency was set to $1 \mathrm{~h}$. Data provided by the global isotope-enabled model ECHAM5 $5_{\text {wiso }}$ (Werner et al., 2011) are used as initial and boundary data as well as for a spectral nudging of the horizontal wind fields above $850 \mathrm{hPa}$. This serves to keep the meteorology close to reality, as the ECHAM5 $5_{\text {wiso }}$ simulation was nudged to ERA-interim reanalyses provided by the European Center for Medium Range Weather Forecasts (ECMWF). The model domain of the $\mathrm{COSMO}_{\text {iso }}$ simulation is chosen such that it covers the dominant moisture source regions of the WAM (see Fig. 2). The model configuration has 40 vertical hybrid levels between the surface and $22.7 \mathrm{~km}$ and a horizontal grid spacing of $14 \mathrm{~km}$ (similar to the horizontal pixel size of Metop/IASI data, Diekmann et al., 2021). Vergara-Temprado et al. (2020) stated that for a horizontal grid spacing below $25 \mathrm{~km}$ switching off the parameterization of deep convection leads to overall better results than increasing the horizontal resolution. Specifically for the WAM, various studies reported significant improvements when using explicit convection (Marsham et al., 2013; Maurer et al., 2017; Martínez \& Chaboureau, 2018; Berthou et al., 2019; Crook et al., 2019; Pante \& Knippertz, 2019). 
Based on these results, we decided not to use a parameterization for deep and shallow convection despite the relatively coarse grid spacing of $14 \mathrm{~km}$.

\subsection{The trajectory tool LAGRANTO}

LAGRANTO is a Lagrangian analysis tool that allows calculating backward and forward air trajectories based on 3D wind fields and tracing physical variables along individual trajectories by interpolating model fields onto the trajectory path (Wernli \& Davies, 1997; Sprenger \& Wernli, 2015). Using the COSMO $_{\text {iso }}$ data from Sect. 3.1 as input, we calculate backward trajectories starting from the Sahelian mid-troposphere during the WAM season 2016. In accordance with the typical residence time of atmospheric water the trajectory length is set to 7 days (Sodemann, 2020). Trajectories are started daily at 09 and 21 UTC from 08 June to 30 July 2016, at 575 and $625 \mathrm{hPa}$ and for approximately every $1^{\circ}$ within the domain from $13^{\circ}-17^{\circ} \mathrm{N}, 8^{\circ} \mathrm{W}-8^{\circ} \mathrm{E}$ (see Fig. 2). In total, this results in 12,720 trajectories. In addition to various meteorological variables, we trace the specific contents $q_{x}$ of $\mathrm{H}_{2} \mathrm{O}$ and $\mathrm{HDO}$ in vapor, sedimenting (rain and snow) and non-sedimenting condensates (liquid and ice clouds). As the trajectory setup is chosen to match the characteristics of the remotely sensed $\left\{\mathrm{H}_{2} \mathrm{O}, \delta \mathrm{D}\right\}$ data from Metop/IASI (Diekmann et al., 2021), we convert $q_{v}$ for $\mathrm{H}_{2} \mathrm{O}$ and $\mathrm{HDO}$ into volume mixing ratios (ppmv) and calculate $\delta \mathrm{D}_{v}$ along each trajectory. We will refer to the starting point (first calculation step, day 0) as the target time and to the last calculation step (day -7) as the trajectory origin.

\subsection{Trajectory sorting}

For a meaningful interpretation of the full ensemble of 12,720 trajectories, the trajectories will be sorted according to geographical and meteorological criteria along their atmospheric pathways. By considering the geographical position and altitude of the trajectory origins, we aim to build clusters that represent the dominant transport patterns of the WAM (Niang et al., 2020). As transport is an important control factor for atmospheric moisture, such a dynamical clustering will give a useful first overview of the characteristic moisture evolution of the defined clusters (Nieto et al., 2006; Salih et al., 2015; Sy et al., 2018).

Further, a trajectory will be classified as precipitating, if its rain content $q_{r}$ accumulated over the whole pathway exceeds the rather arbitrarily chosen threshold of $2 \mathrm{~g} \mathrm{~kg}^{-1}$. 
Analogously, if the accumulated rain content is lower than $0.2 \mathrm{~g} \mathrm{~kg}^{-1}$, the trajectory is assumed to be non-precipitating. An individual trajectory data point is classified as precipitating, if the specific content ( $q_{r}$ for rain, $q_{s}$ for snow) is at least $10^{-5} \mathrm{~g} \mathrm{~kg}^{-1}$. If both $q_{r}$ and $q_{s}$ fulfil this criterion, this precipitation is viewed as mixed-phase. Following the moisture source attribution of Sodemann et al. (2008), we attribute a moisture uptake along a trajectory to surface evaporation if the corresponding trajectory altitude $z_{\text {tra }}$ is below the boundary layer height $z_{\mathrm{bl}}$. As models tend to underestimate the boundary layer height, Sodemann et al. (2008) recommended for this purpose a scaling of $z_{\mathrm{bl}}$ with a factor of 1.5 .

\subsection{Trajectory-based process attribution of $\left\{\mathrm{H}_{2} \mathrm{O}, \delta \mathrm{D}_{v}\right\}$ pairs}

The aim of this work is to establish a framework for interpreting the isotopic composition in a region of interest with regard to moist processes occurring during the transport of air masses arriving in this region. For this purpose, we develop a process attribution procedure by considering temporal changes not only in $\mathrm{H}_{2} \mathrm{O}$ (as performed in Dütsch et al., 2018), but also in $\delta \mathrm{D}_{v}$, thereby making use of the additional isotope information. The general concept behind our Lagrangian process attribution procedure is the following:

1. Definition of processes of interest that shall be identified in the $\left\{\mathrm{H}_{2} \mathrm{O}, \delta \mathrm{D}_{v}\right\}$ phase space

2. Categorization of trajectories or individual segments along trajectories that correspond to the processes of interest

3. Interpretation of the isotopic composition in the region of interest by means of the categorized trajectories

We will use the idealized process curves of Fig. 1 describing effects of air mass mixing, Rayleigh condensation, and Super-Rayleigh signals as the processes of interest (step 1). To illustrate the plausibility of those curves, we will first evaluate them against the isotopic evolution along three characteristic example trajectories. Then, following Sect. 3.3, we sort the trajectories into dominant transport patterns and evaluate their $\left\{\mathrm{H}_{2} \mathrm{O}, \delta \mathrm{D}_{v}\right\}$ signals in order to link segments of trajectories to the proposed process curves (step 2). In turn, this provides statistical information of the relative process occurrence frequencies within the full trajectory ensemble, which eventually facilitates an improved inter- 


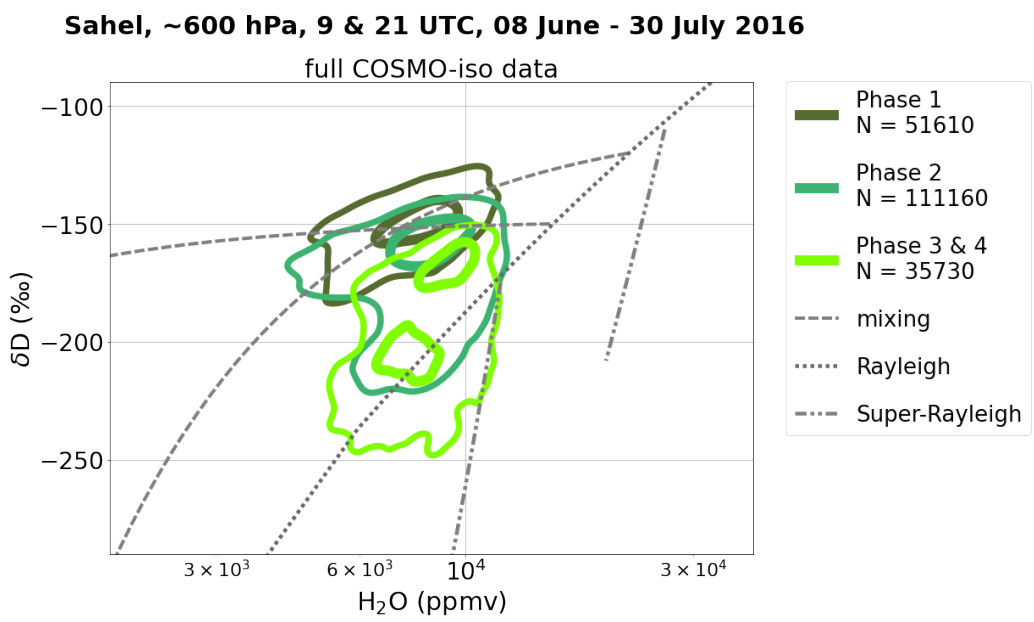

Figure 3. $\left\{\mathrm{H}_{2} \mathrm{O}, \delta \mathrm{D}_{v}\right\}$ pair distributions of the full simulation output of $\mathrm{COSMO}_{\text {iso }}$ in the Sahelian mid-troposphere (600 hPa, see dashed box in Fig. 2) during 08 June-30 July 2016. The two-dimensional contours indicate the data distributions during the different monsoon stages as described by Knippertz et al. (2017). For each stage, the contours summarize 50 and $95 \%$ of the respective data points with the respective total numbers given in the legend. Additionally, this plot includes the idealized process curves that are marked with arrows in Fig. 1.

pretation of the isotopic composition in the target region and the atmospheric processes that determine this composition (step 3).

\section{Lagrangian Analysis of the Sahelian Troposphere}

In this section we apply the proposed Lagrangian process attribution procedure to $\left\{\mathrm{H}_{2} \mathrm{O}, \delta \mathrm{D}_{v}\right\}$ pair distributions in the Sahelian troposphere during the WAM 2016. We refer to the terminology of Knippertz et al. (2017), where the early monsoon period in 2016 was classified based on the difference of averaged precipitation between the Sahel and the Guinean coastal zone. During the pre-onset stage (Phase 1, 01-21 June 2016) the rainfall maximum lied over the Guinea Coast. The shift to the Sahel initiated the post-onset phase (Phase 2, 22 June-20 July 2016). In Phase 3 (21-26 July 2016) an unusual westerly regime formed and caused widespread precipitation over large parts of West Africa, while the circulation returned to undisturbed monsoon conditions in Phase 4 (2731 July 2016). As both Phases 3 and 4 consist only of a few days, we merge them in the following in order to obtain a reasonable data ensemble size. 


\subsection{Average $\left\{\mathrm{H}_{2} \mathrm{O}, \delta \mathrm{D}_{v}\right\}$ development along the West African Monsoon}

Figure 3 emphasizes the added value of $\delta \mathrm{D}_{v}$ compared to traditional humidity measures. It shows the average $\left\{\mathrm{H}_{2} \mathrm{O}, \delta \mathrm{D}_{v}\right\}$ behaviour over the Sahel at $600 \mathrm{hPa}$ during the three monsoon stages, as given by the $\mathrm{COSMO}_{\text {iso }}$ grid point values in the considered domain. The $\left\{\mathrm{H}_{2} \mathrm{O}, \delta \mathrm{D}\right\}$ pair data are summarized by normalized two-dimensional histogram contours (calculated according to Eckstein et al., 2018).

While $\mathrm{H}_{2} \mathrm{O}$ remains within a similar data range throughout the whole period, $\delta \mathrm{D}$ reveals a change with time. In particular, the development of the monsoon circulation in Phase 2 coincides with a shift of $\delta \mathrm{D}$ towards markedly lower values. The very wet Phases 3 and 4 show a shift to higher moisture content and lower $\delta \mathrm{D}$ with respect to Phase 2 . Therefore, this figure suggests that there may be moist processes whose effects can be observed more clearly in the paired $\left\{\mathrm{H}_{2} \mathrm{O}, \delta \mathrm{D}_{v}\right\}$ phase space than in individual $\mathrm{H}_{2} \mathrm{O}$ distributions. In this context, the backward trajectories serve to understand the mechanisms controlling the $\left\{\mathrm{H}_{2} \mathrm{O}, \delta \mathrm{D}_{v}\right\}$ variability, as they shed light on the history of the air masses arriving at the target region.

\subsection{Isotopic process attribution along single trajectories}

As a first step of the Lagrangian process analysis, we choose three individual trajectories: T1 as non-precipitating trajectory, T2 as trajectory with an accumulated $q_{r}$ between 0.2 and $2 \mathrm{~g} \mathrm{~kg}^{-1}$ and T3 as precipitating trajectory (see Sect. 3.3). We analyze their $\left\{\mathrm{H}_{2} \mathrm{O}, \delta \mathrm{D}_{v}\right\}$ evolution to demonstrate how the idealized process curves from Fig. 1 can be interpreted for individual air parcels. The target dates of T1, T2 and T3 are 09 UTC 05 July, 21 UTC 23 June and 09 UTC 19 July 2016. Figure 4 provides an overview of the properties of the chosen trajectories. The dominant mixing and microphysical processes along the trajectories are identified according to the temporal evolution of $\left\{\mathrm{H}_{2} \mathrm{O}\right.$, $\left.\delta \mathrm{D}_{v}\right\}$ pairs and depending on the occurrence of hydrometeors. Arrows and markers illustrate the corresponding temporal evolutions in the $\left\{\mathrm{H}_{2} \mathrm{O}, \delta \mathrm{D}\right\}$ phase space.

The first trajectory $\mathrm{T} 1$ does not show any significant precipitation along its pathway. It starts with a relatively dry signature at around $2.5 \mathrm{~km}$ above the Mediterranean Sea near Sicily (Point 1) and then crosses the Libyan coast (Point 2, Fig. 4a). During this time the trajectory moistens and enriches due to ocean evaporation. Therefore, in Fig. $4 \mathrm{~d}$ the $\left\{\mathrm{H}_{2} \mathrm{O}, \delta \mathrm{D}_{v}\right\}$ pairs follow the moist mixing line according to the blue arrow 

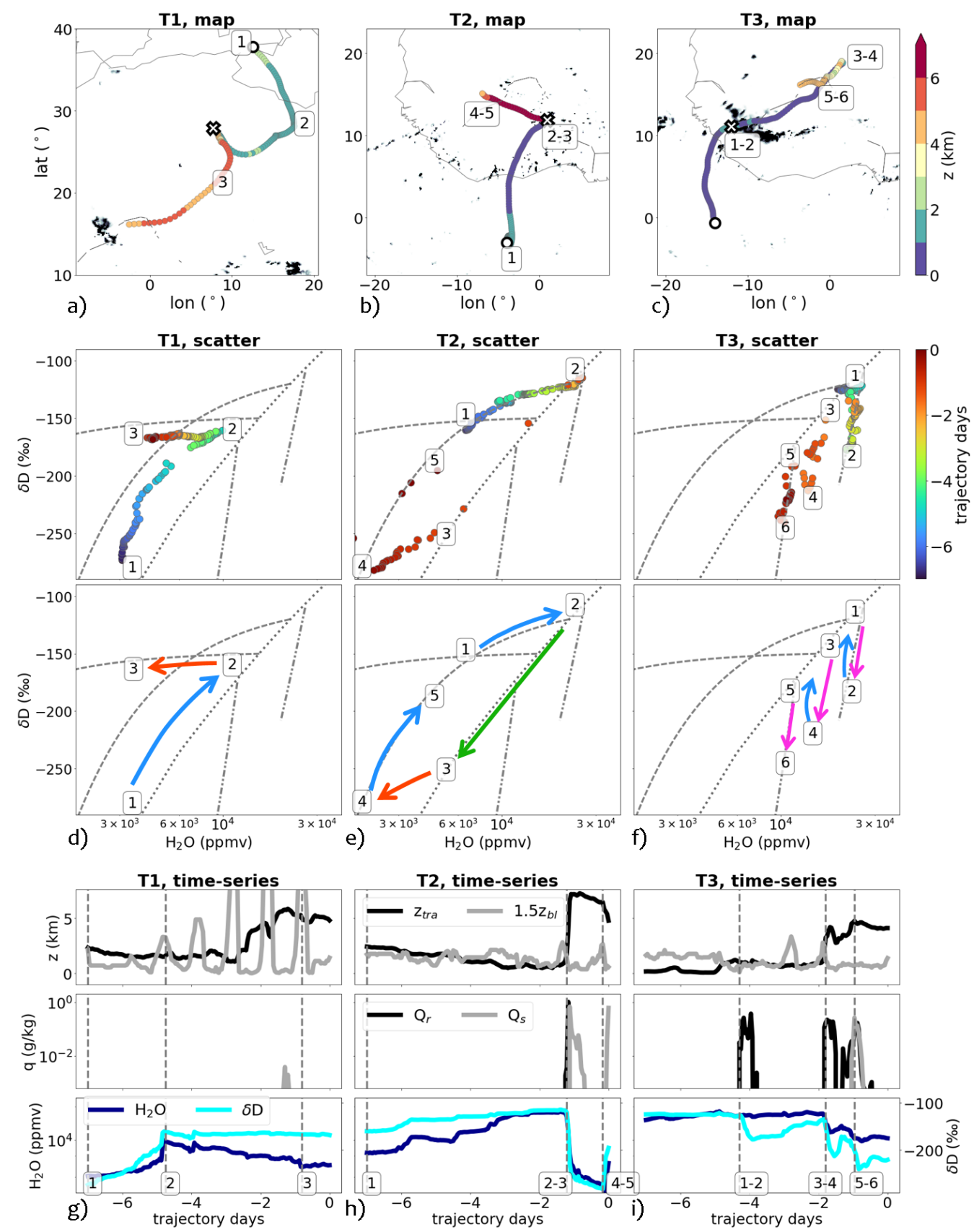

Figure 4. Overview of the trajectories T1, T2, and T3. (a), (b), and (c) show the geometrical pathways, color-coded with altitude. The black framed circle marks the trajectory origin. The black shades indicate areas with a rainfall $>2 \mathrm{~mm} \mathrm{hr}^{-1}$ during the trajectory step marked with $\mathrm{x}$. (d), (e) and (f) show the evolution in the $\left\{\mathrm{H}_{2} \mathrm{O}, \delta \mathrm{D}\right\}$ phase space. The main variations between characteristic signals (marked with numbers) are illustrated with arrows (arrow colors according to Fig. 1). (g), (h) and (f) show the time series of the altitude $\left(z_{\text {tra }}\right)$, boundary layer height $\left(z_{\mathrm{bl}}\right)$, rain $\left(q_{r}\right)$ and snow content $\left(q_{s}\right), \mathrm{H}_{2} \mathrm{O}$ and $\delta \mathrm{D}$ along the respective trajectory. 
from marker 1 to 2. After this, dehydration sets in over the dry North African desert areas. At $30^{\circ} \mathrm{N}, \mathrm{T} 1$ experiences a strong lifting to $4 \mathrm{~km}$ (see marker " $\mathrm{x}$ " in Fig. 4a), where it mixes with dryer mid-tropospheric air and moves southwestward. While $\mathrm{H}_{2} \mathrm{O}$ decreases, $\delta \mathrm{D}_{v}$ remains mostly constant, leading to a mixing signature that follows the dry mixing curve (see orange arrow from 2 to 3 ).

T2 (middle column in Fig. 4) represents a trajectory with both strong mixing and precipitating effects. It originates in the lower troposphere $\left(z_{\text {tra }} \sim 3 \mathrm{~km}\right)$ over the Gulf of Guinea and exhibits moistening and enrichment, while subsiding below $1 \mathrm{~km}$ and taking course towards the Guinea Coast. This moistening is associated with surface evaporation, while the trajectory penetrates into the boundary layer (Fig. 4h). This leads to an enrichment following the moist mixing line (see blue arrow from marker 1 to 2, in Fig. 4e) and results in higher moisture contents than for T1. Over the Sahel, a local convection event (see precipitation patterns in Fig. $4 \mathrm{~b}$ ) lifts the trajectory abruptly from $\sim 1$ to $6 \mathrm{~km}$ altitude (see marker " $\mathrm{x}$ " in Fig. 4b). As a consequence, precipitation forms and depletes the trajectory of its heavy isotopes in the vapor phase following a clear Rayleigh signature (green arrow from 2 to 3 in Fig. 4e). Thereafter, the air parcel appears to leave the convective cell and weak mixing with drier surrounding air occurs (orange arrow, from 3 to 4), leading to a less steep evolution than a pure Rayleigh process would imply. From 4 to 5 , a slight moistening due to mixing appears (blue arrow), as the trajectory subsides down to $\sim 4.5 \mathrm{~km}$.

For the third, precipitating trajectory T3 (right column in Fig. 4) the starting point is already associated with very moist and isotopically enriched conditions, as it is located near the surface of the tropical Atlantic $\left(z_{\text {tra }}<200 \mathrm{~m}\right)$ and is therefore strongly affected by surface evaporation over the relatively warm waters southwest of West Africa. After reaching the West African land mass, the trajectory crosses a westward propagating squall line (see precipitation patterns and marker " $x$ " in Fig. 4c). Large rain drops fall through the air parcel, while the air parcel remains constantly at an altitude in the range of $1-2 \mathrm{~km}$, hence without being lifted by convection. This suggests that this rain formed at higher altitudes and fell from above into the considered air parcel. While $\mathrm{H}_{2} \mathrm{O}$ remains high during this event, $\delta \mathrm{D}_{v}$ shows a sharp drop by more than $50 \%$ (Fig. 4f, magenta arrow from marker 1 to 2 ). This depletion is stronger than would be predicted using the Rayleigh model and thus penetrates into the Super-Rayleigh regime. Along its northeastward path over the Sahel, the trajectory first enriches, likely due to surface evap- 
otranspiration (blue arrow from 2 to 3), until it finally interacts with a second squall line and exhibits once again an isotopic pull towards the Super-Rayleigh regime (magenta arrow from 3 to 4 ). However, at this time the air parcel is lifted to $4 \mathrm{~km}$ and changes its flow direction by $180^{\circ}$, consistent with the propagation direction of the squall line. A subsequent enrichment (blue arrow from 4 to 5) defines the isotopic composition for the injection into the next convective updraft, where the occurrence of snow particles (Fig. 4i) is accompanied by Super-Rayleigh signals (magenta arrow from 5 to 6 ).

In summary, the analysis of the selected trajectories reveals that, by using the theoretical process curves from Fig. 1, the temporal evolution of $\left\{\mathrm{H}_{2} \mathrm{O}, \delta \mathrm{D}_{v}\right\}$ pairs along air parcels can be divided into moist and dry mixing, drying and depletion due to Rayleigh condensation, and processes that deplete the vapor beyond the prediction by the Rayleigh model. Only by considering the whole isotopic history of an air parcel, it is possible to fully explain its target position in the $\left\{\mathrm{H}_{2} \mathrm{O}, \delta \mathrm{D}_{v}\right\}$ phase space.

\subsection{Identification of dominant transport patterns}

In the next step, the aim is to test the usefulness of the idealized process curves for interpreting larger trajectory ensembles during the monsoon period 2016. Therefore, as discussed in Sect. 3.4, we first sort the full ensemble of 12,720 trajectories into meteorologically meaningful clusters of trajectories that experience a similar moisture history. Taking into account the characteristic regions of the trajectory origins as well as the relative position of origin altitude against target altitude, we roughly distinguish between rising (R1 to R3) and subsiding (S1 and S2) transport clusters (see Sect. 3.3). Their main averaged properties (see Fig. 5 and 6 ) are briefly characterized:

R1 This cluster represents the southerly monsoon inflow (dark red trajectories in Fig. 5), originating from the lower troposphere over the Gulf of Guinea with high contents of $\mathrm{H}_{2} \mathrm{O}$ and $\delta \mathrm{D}_{v}$ (see Fig. $6 \mathrm{c}$ and d). It advances on an anticyclonic path towards the Sahel, where it is lifted into the middle troposphere due to moist convection (see Fig. 6a; Marsham et al., 2013). This ascent into colder and dryer regions is associated with intense precipitation (Fig. 6e and f), leading to a strong depletion in $\delta \mathrm{D}_{v}$ (Fig. 6d).

R2 The orange trajectories in Fig. 5 indicate the subtropical Atlantic low-level inflow with the trade winds that get deflected eastward towards the Sahel as a response 

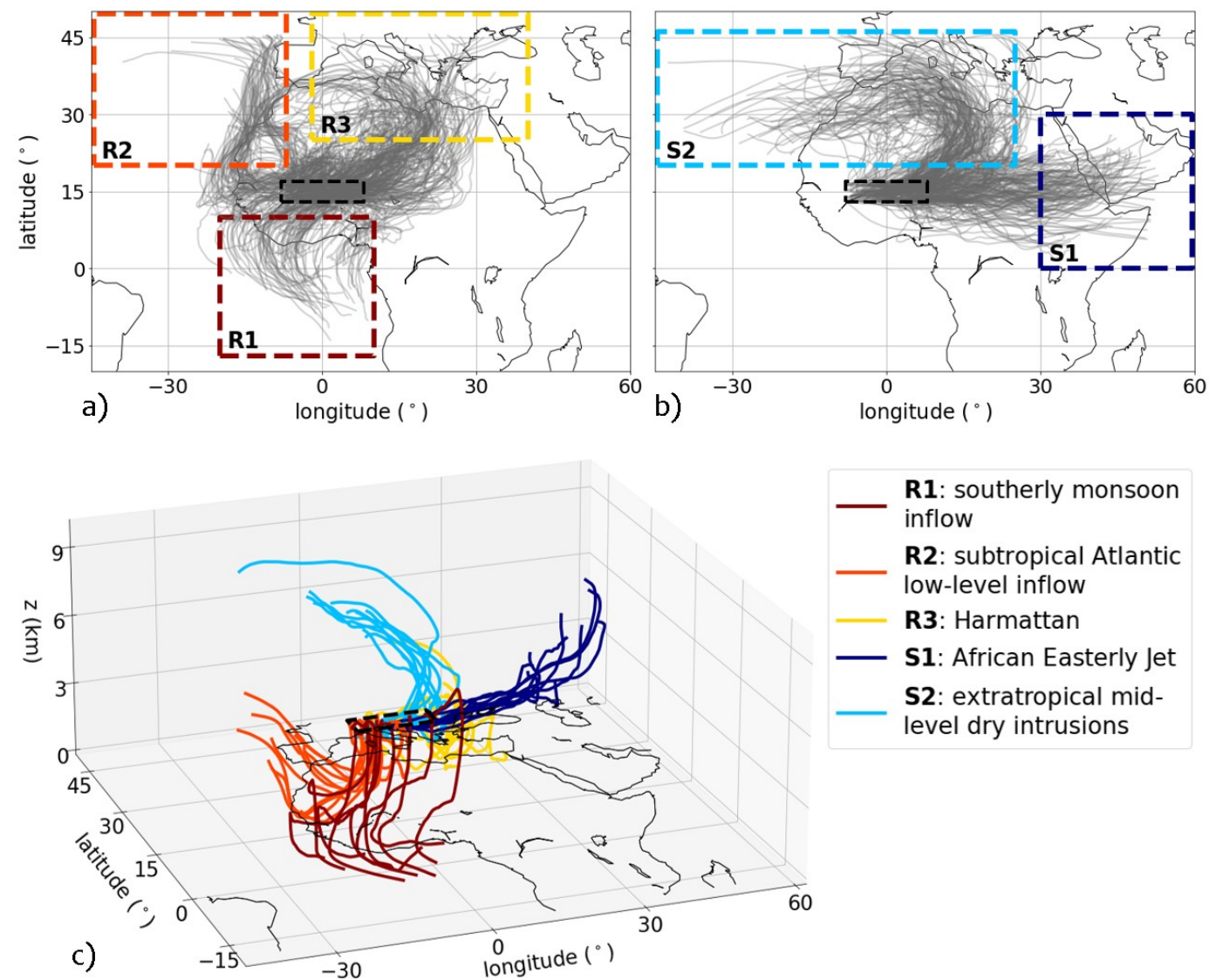

R1: southerly monsoon

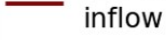

R2: subtropical Atlantic

- low-level inflow

R3: Harmattan

S1: African Easterly Jet

S2: extratropical midlevel dry intrusions

Figure 5. Trajectory clusters for (a) the monsoon inflow (R1, dark red box), the low-level subtropical Atlantic inflow (R2, orange), the Harmattan (R3, yellow), and (b) the African Easterly Jet (S1, dark blue) and the extratropical dry intrusions (S2, cyan). (c) shows a 3D view of selected trajectories for each transport cluster. The black box marks the target region over the Sahel.

to the Saharan heat low (Nieto et al., 2006; Lavaysse et al., 2009). Its initial moisture is lower than for R1, but increases during the transport over the Atlantic (Fig. 6c and d). Similar to R1, it experiences a convective lifting over the Sahel (Fig. 6a), but ends up with more enriched $\delta \mathrm{D}_{v}$.

R3 The trajectories in yellow (Fig. 5) originate in the lower troposphere over the Mediterranean Sea and follow the Etesian winds towards the African continent (Tyrlis \& Lelieveld, 2013). Over North Africa, this cluster moves along the eastern side of the Atlas mountains and then feeds the relatively dry Harmattan (Hall \& Peyrillé, 2006). As the surface evaporation over North Africa is small, there is hardly any change in moisture (Fig. 6c) as well as no significant contribution to the Sahelian 


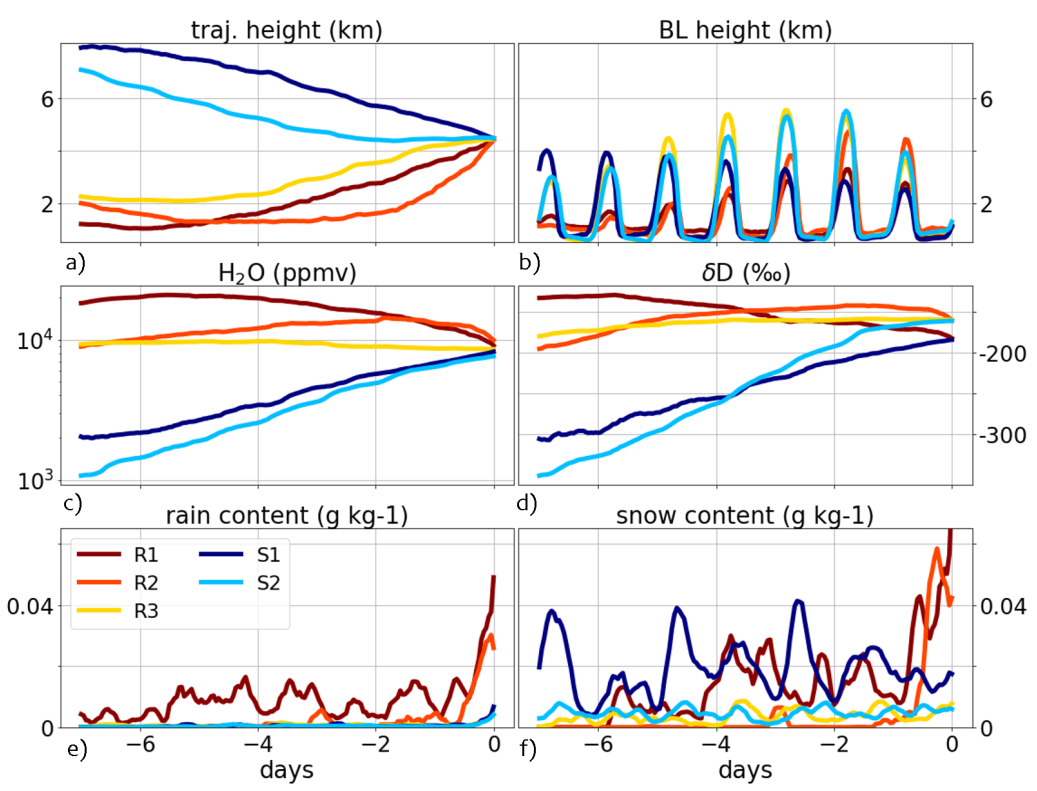

Figure 6. Averaged time series for the transport clusters R1 (dark red), R2 (orange), R3 (yellow), S1 (dark blue) and S2 (cyan). Shown are (a) the trajectory altitude, (b) boundary layer height $\left(1.5 z_{\mathrm{bl}}\right),(\mathrm{c}) \mathrm{H}_{2} \mathrm{O}$, (d) $\delta \mathrm{D}_{v}$, (e) rain content $q_{r}$ and (f) snow content $q_{s}$. For (e) and (f), a running mean over 6 time steps is used. To underline the daily cycles, in particular for the boundary layer height, only the trajectories with the same starting time of 09 UTC at the Sahelian mid-troposphere are herein considered.

precipitation (Fig.6e,f). At the target location, it shows $\delta \mathrm{D}_{v}$ values similar to $\mathrm{R} 2$ (Fig. 6d).

S1 The African Easterly Jet inflow is represented by the dark blue trajectories (Fig. 5). It is characterized by a low-latitude easterly flow that transports dry air masses from the upper troposphere (Fig. 6a) from East Africa down to the Sahelian midtroposphere (Cook, 1999; Sy et al., 2018). Through deep tropical convection, frozen precipitation falls into the AEJ (Fig. 6f). During its subsiding path into moister tropospheric regions, $\mathrm{H}_{2} \mathrm{O}$ and $\delta \mathrm{D}_{v}$ increase and converge towards the values of R1 (Fig. 6c and d).

S2 The cyan trajectory ensemble in Fig. 5 describes extratropical mid-level dry intrusions, which feed into the anticyclonic circulation above the Saharan surface heat low (Cook, 1999; Lavaysse et al., 2009). As this flow originates from the mid-latitude upper troposphere, it reveals very low moisture contents (Roca et al., 2005), even lower than for S1 (Fig. 6c and d). During its subsiding transition towards the Sa- 


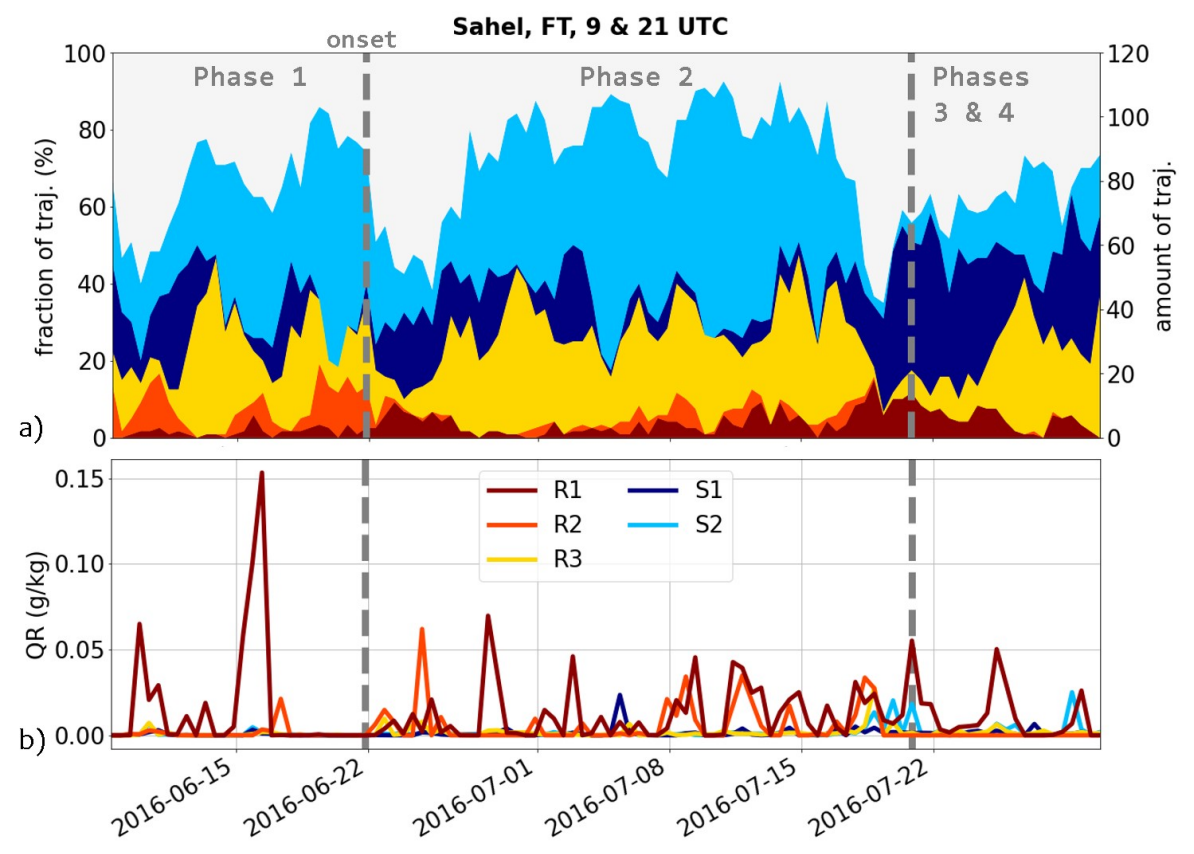

Figure 7. Time series of (a) the relative contribution of each transport cluster to the total amount of trajectories arriving every 12 hours in the target region in the Sahelian free troposphere. The monsoon stages described in Knippertz et al. (2017) are separated by dashed lines.

(b) Rain water content accumulated along the last 12 hours of each trajectory before arriving in the target region and averaged over each cluster.

hel (Fig. 6a), a strong moistening and enrichment takes place. The reason for this evolution is the elevated boundary layer height over the Sahara (Hall \& Peyrillé, 2006), which mixes water vapor into S2 (Fig. 6b). At its target position, its $\delta \mathrm{D}_{v}$ resembles the values of the rising extratropical clusters (R2 and R3).

Figure 7a shows the relative contributions of each transport cluster to the target region as a function of time. The clusters represent together up to $90 \%$ of the air transported into the Sahelian mid-troposphere. The unclassified trajectories mainly originate above the West African continent with no characteristic large-scale transport. Even though the relative contribution of the monsoon inflow (R1) is comparably low in terms of number of trajectories $(<10 \%)$, it is nonetheless the major driver of precipitation for the Sahel during the post-onset stage (Phase 2, e.g. compared to R2 in Fig. 7b). The pre-onset Phase 1 shows marked fluctuations associated with synoptic-scale disturbances described in Knippertz et al. (2017), leading to single rainfall events during June (e.g. Maranan 
et al., 2019). As the monsoon has not fully developed yet, the fraction of trajectories from the subtropical Atlantic (R2) is higher than in the other Phases (Fig. 7a). The actual monsoon onset is characterized by a breakdown and then re-establishment of the AEJ as indicated by the dark blue trajectories S1. The fraction of monsoon trajectories in Phase 2 clearly increases compared to Phase 1 and precipitation events are now more frequent (Fig. 7b). Finally, the unusual flow situation during Phase 3 (and to a lesser extent Phase 4) is reflected in a clear shift of the fractions of transport clusters. Extratropical intrusions almost disappear entirely with a surge in AEJ inflow. The monsoon inflow, which causes marked precipitation events, increases at the expense of the Harmattan inflow.

In summary, the trajectory clustering according to their source regions reflects well the major transport contributions for the Sahelian troposphere during the monsoon season 2016. The clusters separate the trajectories into rising and subsiding transport patterns that bring moist and dry air masses to West Africa from different regions.

\subsection{Isotopic process attribution along transport clusters}

In this section, we investigate the importance of different processes along the transport clusters presented in Sect. 4.3. We address the question to which extent and for which meteorological conditions the mixing, Rayleigh, and Super-Rayleigh process curves from Fig. 1 are useful to explain the isotopic signals along the transport clusters. As these clusters are most representative during the active monsoon (see Fig. 7), we focus in the following on trajectories during the post-onset stage (Phase 2).

\subsubsection{Importance of mixing processes}

As discussed in Sect. 4.2, air mass mixing plays a crucial role for the isotopic evolution along a trajectory, in particular if no rain processes occur. Therefore, to extract pure mixing effects in the $\left\{\mathrm{H}_{2} \mathrm{O}, \delta \mathrm{D}_{v}\right\}$ phase space, we select all non-precipitating trajectories (see Sect. 3.3).

Figure 8 shows the $\left\{\mathrm{H}_{2} \mathrm{O}, \delta \mathrm{D}_{v}\right\}$ pair data along the non-precipitating trajectories for each transport cluster. Even though the rising clusters R1 and R2 show on average strong occurrences of precipitation along their pathways (see Fig. 6e), still non-precipitating trajectories appear for both (7 and 56\%). The non-precipitating trajectories of R1, R2, 


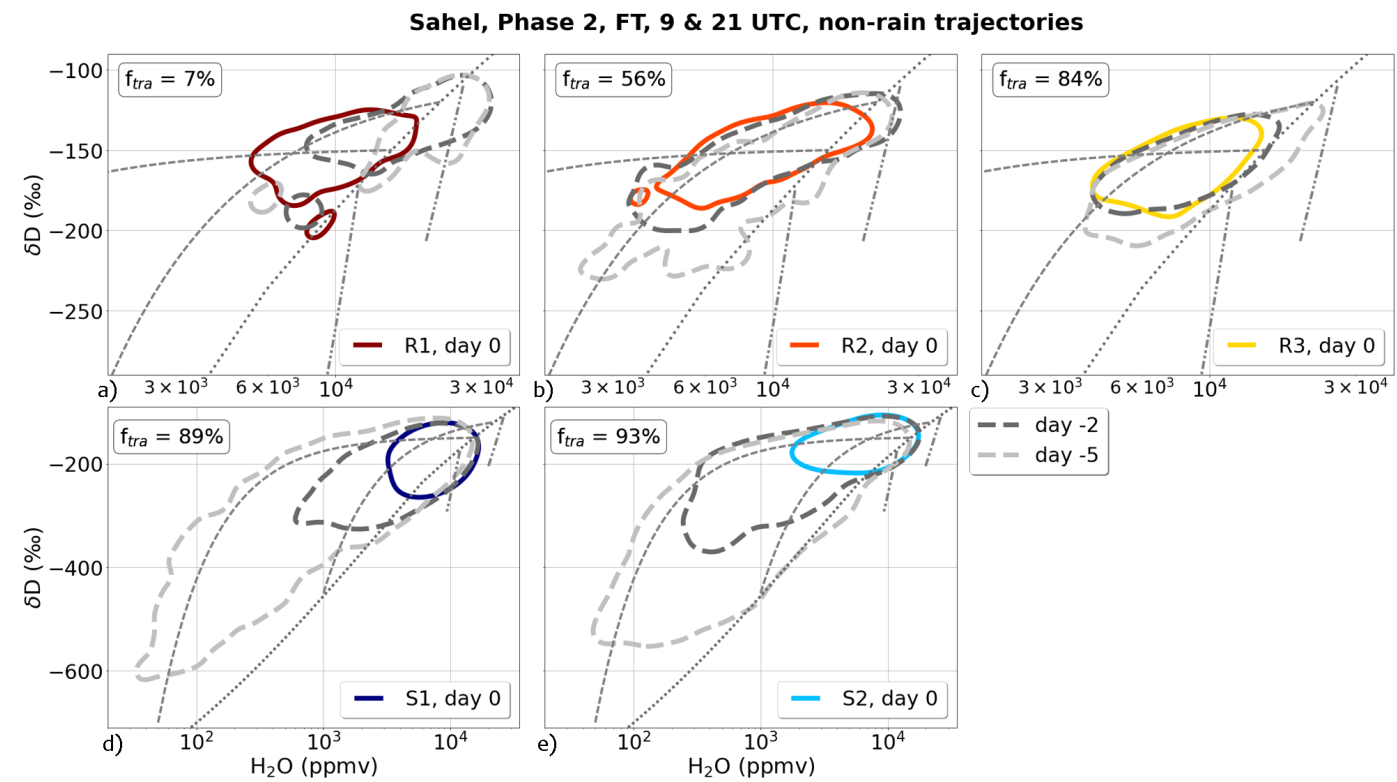

Figure 8. $\left\{\mathrm{H}_{2} \mathrm{O}, \delta \mathrm{D}_{v}\right\}$ pair distributions for the non-precipitating trajectories of each transport cluster. The relative fractions $f_{\text {tra }}$ of corresponding trajectories in each cluster are given in the respective plots. The solid, colored contours comprise $95 \%$ of the data for the last 24 hours of the trajectory before reaching the target region (day 0 ), the dashed, dark gray contours the data of 2 days before arrival and the light gray contours the data of 5 days before arrival. The underlain gray process curves are the same as in Fig. 1. Note the much larger axis ranges shown in the bottom two panels.

and R3 show clear isotopic signals towards the moist mixing line. Moisture uptake from ocean evaporation and continental evapotranspiration represents a very moist mixing member and is opposed to the relatively dry conditions in the free troposphere. For instance, the non-precipitating trajectories in the monsoon cluster R1 (only $7 \%$ ) start with very moist and enriched values above the Gulf of Guinea and subsequently mix with the drier and more depleted mid-tropospheric air masses while they advance over West Africa. Similar mixing structures are apparent for the Atlantic inflow (R2) and the Harmattan (R3), with substantially larger numbers of non-precipitating trajectories (56 and $84 \%$, respectively). As their initial moisture is much more variable than for R1, both moistening and drying occurs along the non-precipitating trajectories of the R2 and R3, closely following the moist mixing curve. 

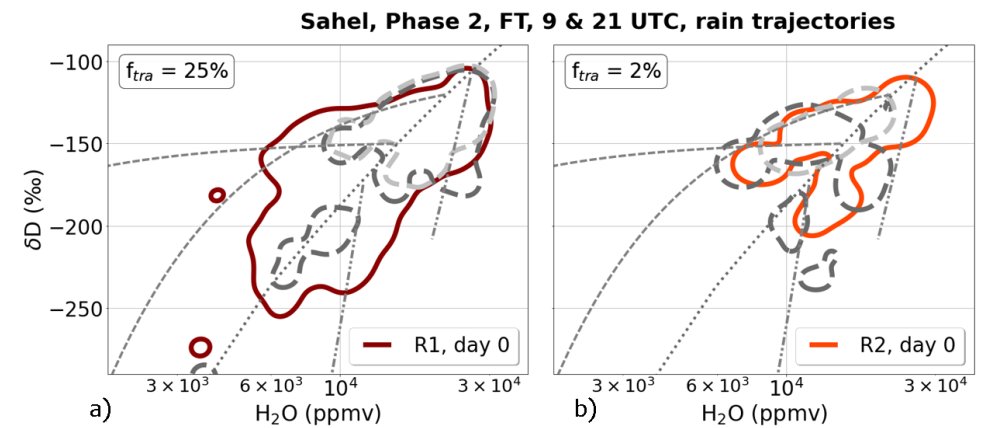

- - day -2

-- day -5

Figure 9. $\left\{\mathrm{H}_{2} \mathrm{O}, \delta \mathrm{D}_{v}\right\}$ pair distributions analogous to Fig. 8, but for the precipitating trajectories of transport clusters R1 and R2 only.

For the subsiding clusters S1 (AEJ) and S2 (extratropical intrusions), the non-precipitating trajectories are predominant $(\sim 90 \%)$. As they typically originate in the upper troposphere, their starting points constitute very dry and depleted end members, while in this case the mid-tropospheric air masses act as moister end members. Thus, during the subsidence of S1 and S2 strong signals along the dry mixing curve develop, until the moisture approaches values similar to the target moisture of the rising trajectories.

In summary, even though the non-precipitating trajectories of the rising and subsiding transport clusters start with significantly different isotopic signals, mixing homogenizes to first order their $\left\{\mathrm{H}_{2} \mathrm{O}, \delta \mathrm{D}_{v}\right\}$ pairs when arriving over the Sahel. Dehydration and moistening along the respective trajectories is well described by the theoretical moist and dry mixing curves.

\subsubsection{Importance of Rayleigh processes}

To identify Rayleigh processes along the transport clusters, we now focus on the precipitating trajectories (see Sect. 3.3). Here, we consider only the transport clusters R1 and R2, because only these two clusters include trajectories that exhibit a significant rain amount and therefore fulfill the rain criterion (see Fig. 7b).

In addition to signatures along the moist mixing curve, a clear Rayleigh signal is evident for both clusters (see Fig. 9). In particular during the last 24 hours before arrival, when the convection peaks, the $\left\{\mathrm{H}_{2} \mathrm{O}, \delta \mathrm{D}_{v}\right\}$ pairs are distributed along the theoretical Rayleigh curve and indicate a depletion that cannot be explained with the mixing curves alone. Additionally, also values appear below the Rayleigh curve. Either this 

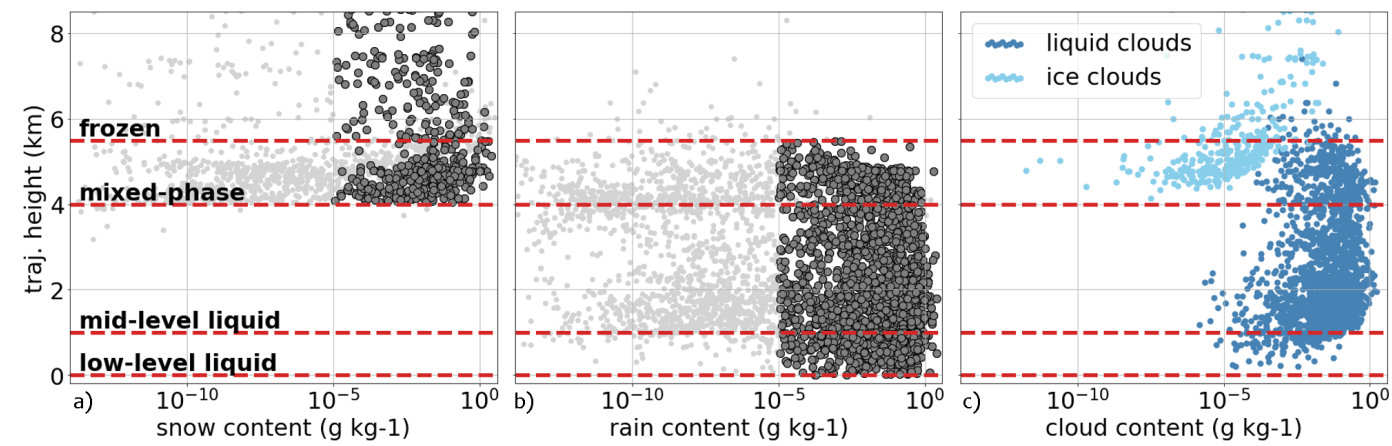

Figure 10. Classification of precipitating segments along the precipitating trajectories of R1. (a) shows snow content $q_{s}$ plotted against the trajectory altitude and (b) the respective rain content $q_{r}$. The dark gray scatter indicate the data points, where the respective precipitation content exceeds $10^{-5} \mathrm{~g} \mathrm{~kg}^{-1}$. In (c), liquid and frozen cloud water contents are plotted against trajectory altitude.

is due to further Rayleigh processes with curves that are shifted towards lower $\delta \mathrm{D}_{v}$ values (which is rather unlikely, since the plotted Rayleigh curve is already chosen for relatively high surface temperature and relative humidity, see Fig. 1), or there are processes that lead to an enhanced depletion and create signals in the Super-Rayleigh area, as documented for trajectory T3 in Sect. 4.2.

\subsubsection{Importance of Super-Rayleigh processes}

This sections sheds light upon the Super-Rayleigh signatures in the $\left\{\mathrm{H}_{2} \mathrm{O}, \delta \mathrm{D}_{v}\right\}$ pair distributions that develop during the precipitating ascent of the monsoon flow (R1) into the Sahelian mid-troposphere.

For this purpose, we take the precipitating trajectories of R1 and further classify the precipitating points of the corresponding trajectories based on the altitude and phase of the precipitation. Following the precipitation thresholds of Sect. 3.3, a distinction is made for frozen $\left(q_{s}\right)$, mixed-phase $\left(q_{s}\right.$ and $\left.q_{r}\right)$, and mid- and low-level liquid $\left(q_{r}\right)$ precipitation. The respective altitude ranges are shown in Fig. 10. While the low-level liquid class represents the near-surface and mostly sub-cloud rain, the other precipitation classes can go along with liquid or frozen clouds (Fig. 10c). Further, we distinguish between saturated $(R H \geq 99 \%)$ and unsaturated $(R H \leq 90 \%)$ conditions of the ambient vapor (Fig. 11a-d). In line with the saturation adjustment of COSMO $_{\text {iso }}$, the unsatu- 

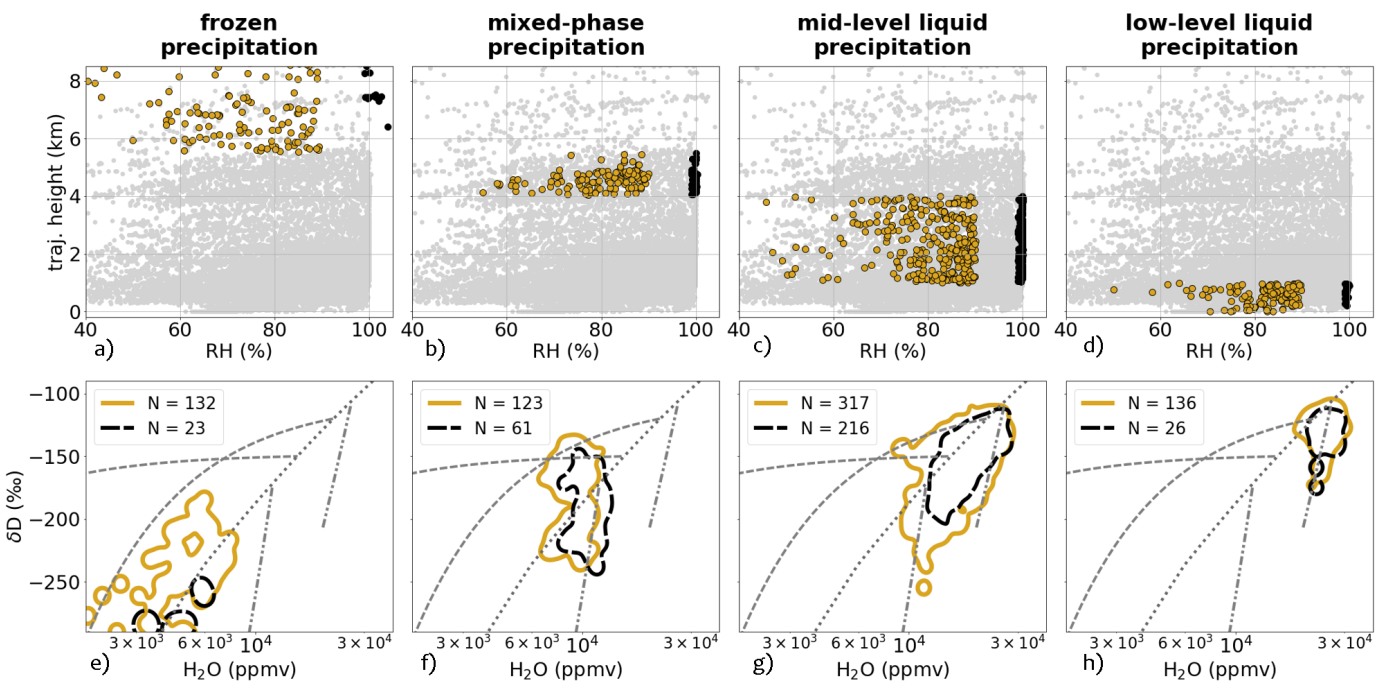

Figure 11. $\left\{\mathrm{H}_{2} \mathrm{O}, \delta \mathrm{D}_{v}\right\}$ pair distributions of water vapor for the different classes of precipitating segments within the transport cluster R1, further separated according to relative humidity. (a)-(d) relative humidity against trajectory altitude with black (golden) dots indicating saturated (unsaturated) conditions. The gray dots show all data points within R1. (e)-(h) display the contours that summarize $95 \%$ of the $\left\{\mathrm{H}_{2} \mathrm{O}, \delta \mathrm{D}_{v}\right\}$ pair data of the ambient water vapor for the saturated (black) and unsaturated (golden) points in the different precipitation classes.

rated data points are cloud-free (near-cloud points may exhibit minor cloud contents due to the 3D interpolation when tracing $q_{c}$ and $q_{i}$ along the trajectories).

Figures 11a, e depict the trajectory points with frozen precipitation $q_{s}$, with only few corresponding data points appearing within the chosen axis range of the $\left\{\mathrm{H}_{2} \mathrm{O}, \delta \mathrm{D}_{v}\right\}$ plot. These snow particles are assumed to have formed at high altitudes, for instance within the deep convective parts of MCSs, and fall through the trajectories on their way down. As sublimation is assumed not to fractionate, the isotopic composition of the ambient vapor gathers around the Rayleigh condensation curve with no significant Super-Rayleigh signals.

If these snow particles fall into the melting zone, where the air temperature is around $\sim 0^{\circ} \mathrm{C}$, an area of mixed-phase precipitation develops (Fig. 11b, f). The melting process itself is non-fractionating, but it initiates fractionating interactions between the newly formed liquid drops and the ambient vapor. The contours in the $\left\{\mathrm{H}_{2} \mathrm{O}, \delta \mathrm{D}_{v}\right\}$ phase space reveal that for both saturated and unsaturated conditions Super-Rayleigh signatures ap- 

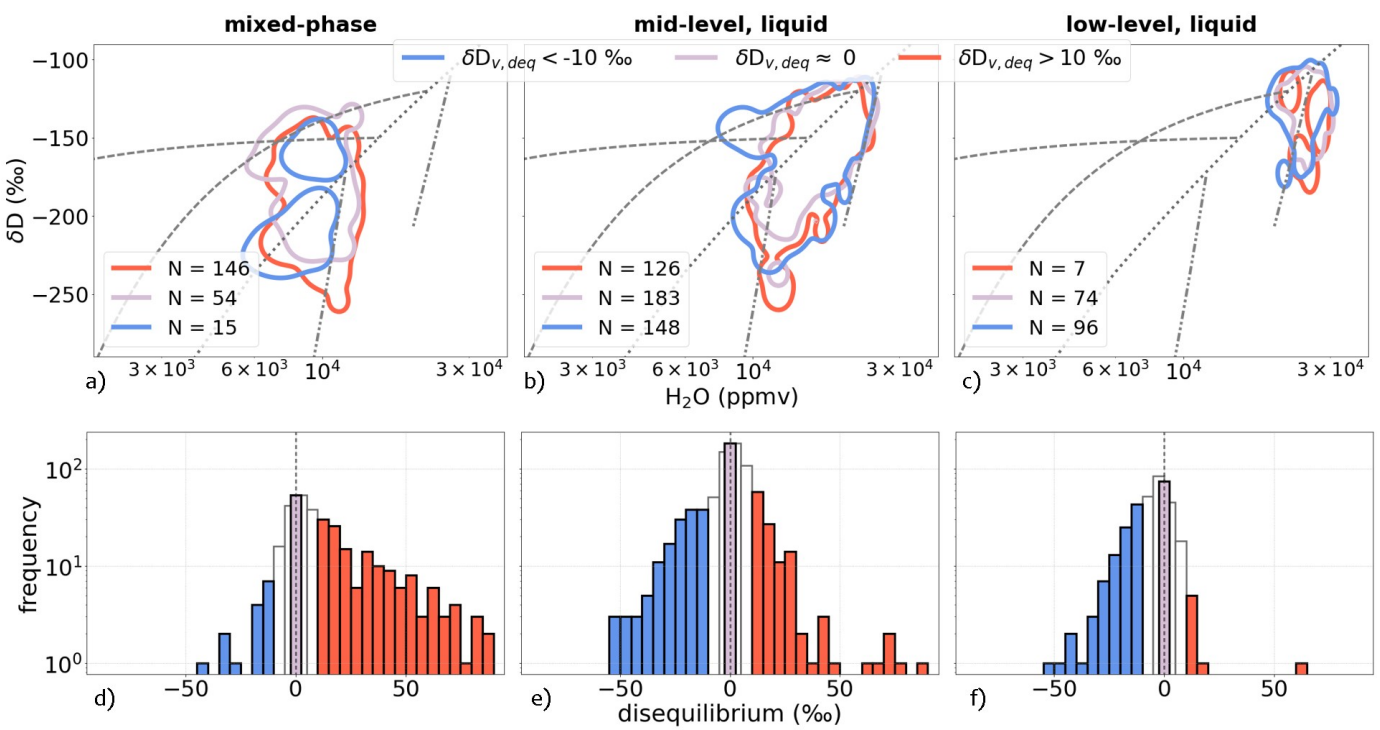

Figure 12. Isotopic disequilibrium $\delta D_{v, \text { deq }}$ between water vapor and rain drops for the precipitation classes from Fig. 10 where liquid precipitation occur. In (a)-(c), the blue contours summarize $95 \%$ of the $\left\{\mathrm{H}_{2} \mathrm{O}, \delta \mathrm{D}_{v}\right\}$ pairs with $\delta \mathrm{D}_{v, \text { deq }}<-10 \%$ (vapor is significantly more depleted in heavy isotopes than the equilibrium vapor from precipitation), the lilac contours pairs with $\left|\delta \mathrm{D}_{v, \text { deq }}\right|<2.5 \%$ (no significant disequilibrium), and the red contours pairs with $\delta \mathrm{D}_{v, \text { deq }}>10 \%$ (vapor is significantly more enriched in heavy isotopes compared to the equilibrium vapor from precipitation). (d)-(f) show the histograms for $\delta \mathrm{D}_{v, \text { deq }}$ for the corresponding classes of precipitation and disequilibrium.

pear. Even in saturated conditions an isotopic flux can occur and equilibrate the rain drops with the ambient vapor. In case of sub-saturation, rain evaporation can take place. Both effects have the potential to further deplete the water vapor (see Sect. 2) and may thus explain the depleted Super-Rayleigh signatures inside the melting zone.

During the sedimentation of the liquid drops through a convective system, the SuperRayleigh signatures are less pronounced for the saturated trajectory points, but still remarkable for unsaturated and cloud-free conditions (Fig. 11c, g). This depletion results, for instance, from rain evaporation in the unsaturated area below the stratiform cloud shield of a squall line.

Figures 11d, h show the trajectory points, where rain drops occur near the surface and below the convective cloud base. Here, the air parcels are mostly unsaturated and indicate sharp tendencies towards the Super-Rayleigh area. In agreement with Risi, Bony, 
and Vimeux (2008), this hints towards effects of sub-cloud rain evaporation in unsaturated downdrafts.

To further improve the distinction between contributions of rain evaporation and isotopic equilibration, we analyze the degree of isotopic disequilibrium $\delta \mathrm{D}_{v, \text { deq }}$ between the vapor and the liquid condensate (see Eqn. 6). Figure 12a, b, c show the distribution of $\delta \mathrm{D}_{v, \text { deq }}$ in the $\left\{\mathrm{H}_{2} \mathrm{O}, \delta \mathrm{D}_{v}\right\}$ phase space for the precipitation classes from Fig. 10 with liquid precipitation. Even though the $\left\{\mathrm{H}_{2} \mathrm{O}, \delta \mathrm{D}_{v}\right\}$ pair distributions for negative, low, and positive disequilibrium are highly similar (Fig. 12a-c), the corresponding histograms of $\delta \mathrm{D}_{v, d e q}$ show fundamental differences (Fig. 12d-f). In the melting zone, we observe a strong imbalance towards positive values of $\delta \mathrm{D}_{v, \text { deq }}$, i.e. the vapor in equilibrium with the rain drops would be more depleted than the actual vapor (Fig. 12d). These rain drops have formed from melting snow and therefore reflect the isotopic composition at the condensation altitudes of the snow particles. Within deep convective systems, condensation can occur up to the tropopause level, imprinting highly depleted signatures on the precipitation (Celle-Jeanton et al., 2004; Risi, Bony, \& Vimeux, 2008). If saturated conditions prevail at lower altitudes, the fall of this precipitation with low $\delta \mathrm{D}_{r}$ through a region with relatively higher $\delta \mathrm{D}_{v}$ induces an equilibrating isotopic flux from the vapor to rain. This decreases $\delta \mathrm{D}_{v}$, while $\mathrm{H}_{2} \mathrm{O}$ remains constant, contributing to the development of Super-Rayleigh signals within the melting zone (Fig. 12a). With decreasing height, the histogram of $\delta \mathrm{D}_{v, d e q}$ shifts to lower values (Fig. 12e), while equilibration and rain evaporation proceed and reduce the grade of disequilibrium (see Sect. 2). Eventually, in the sub-cloud zone the imbalance in $\delta \mathrm{D}_{v, \text { deq }}$ changes sign (Fig. 12f), featuring equilibrium vapor from precipitation with a higher $\delta \mathrm{D}$ than the sub-cloud vapor. As here unsaturated conditions prevail (Fig. 11h), rain evaporation is strongly enhanced, leading to an enrichment of heavy isotopes in the rain drops and as a consequence to negative $\delta \mathrm{D}_{v, d e q}$.

Figures 11 and 12 reveal another interesting feature with more enriched values towards the mixing curves (at around $-150 \%$ ). In particular for the mid-level liquid precipitation, a clear mixing signal stands out that correlates with sub-saturation (Fig. 11g) and negative disequilibrium (Fig. 12b). We suspect that this feature is a result of synopticscale intrusions that transport dry and depleted air masses as rear-to-front flow into a convective system (Kurita, 2013). 


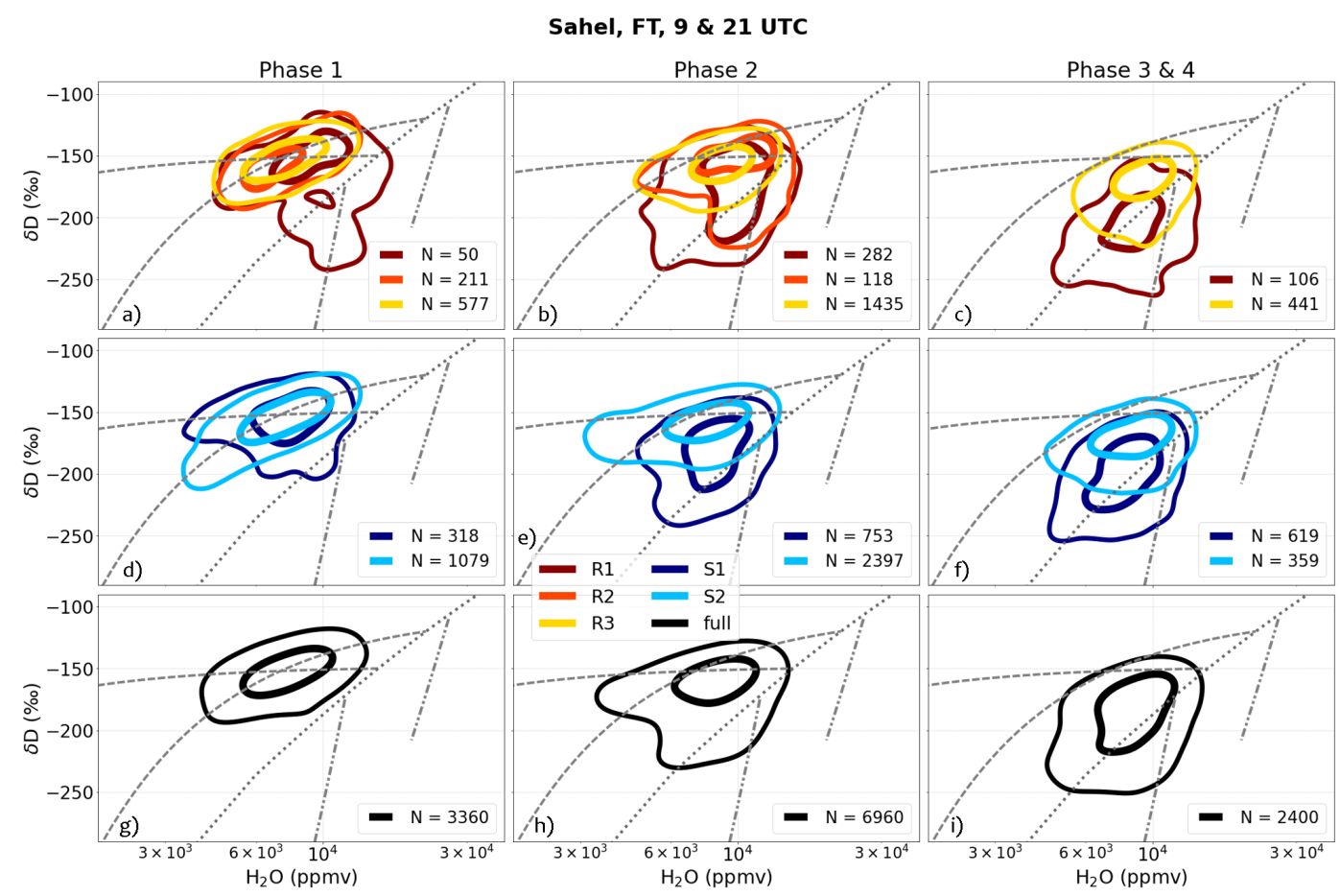

Figure 13. $\left\{\mathrm{H}_{2} \mathrm{O}, \delta \mathrm{D}_{v}\right\}$ pair distributions in the target region (Sahelian free troposphere) for each transport cluster (colors, see Fig. 5) and monsoon phase in 2016 (columns, see introductory text of Sect. 4). The shown contours mark 50 and $95 \%$ of all data points for (a)-(c) clusters R1, R2, and R3, (d)-(f) clusters S1 and S2, and (g)-(i) all trajectories.

In summary, to account for the Super-Rayleigh signals in water vapor in the presence of precipitation, it is not sufficient to think of an isolated process but rather to consider the full interaction of microphysical processes that occur within and around a convective cell. The depletion due to Rayleigh condensation during the convective updraft is superposed by additional depleting contributions of evaporation and equilibration of the falling rain drops. However, the two Super-Rayleigh lines marked in the $\left\{\mathrm{H}_{2} \mathrm{O}, \delta \mathrm{D}_{v}\right\}$ phase space constitute rough bounds for the Super-Rayleigh area, as they frame the altitude range, where interactions between vapor and liquid precipitation can occur (from the melting zone to the surface).

\subsection{Understanding $\left\{\mathrm{H}_{2} \mathrm{O}, \delta \mathrm{D}_{v}\right\}$ pair distributions over the target region}

In the discussion of Fig. 3 we have already noted that $\mathrm{COSMO}_{\text {iso }}$ simulates markedly different isotopic distributions in the Sahelian free troposphere during the three mon- 
soon phases documented in Knippertz et al. (2017) (see Sect. 4.1). By combining the attributed signals in the $\left\{\mathrm{H}_{2} \mathrm{O}, \delta \mathrm{D}_{v}\right\}$ phase space along the transport clusters, we can now examine to which extent mixing and microphysical processes along the trajectory pathways explain this temporal evolution. To this end, Fig. 13 shows the same two-dimensional histogram contours for $\left\{\mathrm{H}_{2} \mathrm{O}, \delta \mathrm{D}_{v}\right\}$ pairs as in Fig. 3 but now separated by transport cluster. As a reference, results for the five transport clusters combined are also provided (Fig. 13g-i).

A direct comparison to Fig. 3 reveals that the $\left\{\mathrm{H}_{2} \mathrm{O}, \delta \mathrm{D}_{v}\right\}$ pairs of the full trajectory ensemble (Fig. 13) are in line with the full $\mathrm{COSMO}_{\text {iso }}$ grid point values (Fig. 13). During the pre-onset stage (Phase 1 ) the $\left\{\mathrm{H}_{2} \mathrm{O}, \delta \mathrm{D}_{v}\right\}$ distribution is governed by (mostly dry) mixing processes between moister and drier air masses that converge along the ITD. After the monsoon onset (Phase 2), convective processes (i.e., condensation, evaporation, and diffusive equilibration of rain drops) prevail and lead to a strong shift of $\delta \mathrm{D}_{v}$ towards the Rayleigh and Super-Rayleigh areas. This shift can temporally be enhanced during particularly wet monsoon periods (Phase 3 and 4). As the contours of the full trajectory ensemble result from contributions of each transport cluster (Fig. 7), their individual inspection allows for further disentangling the isotopic variability during the monsoon.

During the pre-onset stage (Phase 1; left column in Fig. 13) all clusters reveal robust and similar isotopic signals along the mixing curves. Despite the significantly different mixing history of the rising (R1, R2 and R3) and the subsiding (S1 and S2) clusters, two-way mixing harmonizes their $\left\{\mathrm{H}_{2} \mathrm{O}, \delta \mathrm{D}_{v}\right\}$ pairs in the Sahelian troposphere. Only within the monsoon inflow (R1, red contours) occasional convective events create departures from the mixing curves towards the Rayleigh and Super-Rayleigh lines. The dominating extratropical intrusion cluster S2 (cyan contours, 1079 trajectories) agrees well with R2 and R3 but with a tendency towards drier and more depleted air. In contrast, the AEJ cluster S1 (dark blue contours) shows mild indications of both mixing along the dry mixing line and towards the Rayleigh and Super-Rayleigh area. Consequently, the contours for all trajectories combined are dominated by mixing along the moist mixing curve.

With the transition to the post-onset stage (Phase 2; middle column in Fig. 13), the frequent convection over the Sahel causes a general shift from relatively enriched air 
towards lower $\delta \mathrm{D}_{v}$, while $\mathrm{H}_{2} \mathrm{O}$ remains high. The condensation processes associated with the monsoon convection pushes the $\left\{\mathrm{H}_{2} \mathrm{O}, \delta \mathrm{D}_{v}\right\}$ pair distributions of $\mathrm{R} 1$ and $\mathrm{R} 2$ towards the Rayleigh line. Additionally, the increased convection enhances effects such as diffusive equilibration and partial rain evaporation. Since we here consider data in the free troposphere, i.e., in the melting zone of falling snow particles, strong isotopic signals develop for R1 and R2 towards the lower Super-Rayleigh line. Because of the strong relation of monsoon precipitation with the air masses transported by the AEJ (Sy et al., 2018; Niang et al., 2020), the isotopic composition of cluster S1 merges with the signals of R1. By contrast, the northwesterly subtropical clusters R3 (Harmattan) and S2 (extratropical mid-level dry intrusions) remain around the mixing curves with only slight tendencies towards the Rayleigh curve. This emphasizes the existence of a subtropical mixing barrier that hinders the isotopic exchange between subtropical and tropical transport clusters as discussed in Yang and Pierrehumbert (1994) and Niang et al. (2020). The resulting contrast between the effects of mixing and microphysical processes are well represented in the contours of the full ensemble.

Finally, in the unusually wet Phases 3 and 4 (right column in Fig. 13) the tendencies towards moister and less enriched air amplify. The monsoon inflow (R1) and the AEJ inflow (S1) further drop to lower $\delta \mathrm{D}_{v}$, as convective processes increase and foster Rayleigh and Super-Rayleigh signatures. During this period convection is so widespread that also the sub-tropical clusters R3 and S2 show indications of reduced mixing and increased Rayleigh signals. As already shown in Fig. 7, the low-level Atlantic inflow cluster R2 is not present during these phases (Knippertz et al., 2017). The isotopic composition of all trajectories clearly reflects the shift from the mixing to the Rayleigh line with a marked extension towards the Super-Rayleigh area.

To summarize, the comparison of the $\left\{\mathrm{H}_{2} \mathrm{O}, \delta \mathrm{D}_{v}\right\}$ pairs of the transport clusters from Fig. 13 against the $\mathrm{COSMO}_{\text {iso }}$ grid point values from Fig. 3 reveals that the identified process curves along different transport pathways provide a useful framework for better understanding the actual evolution of the isotopic composition in the Sahelian midtroposphere during the WAM. 


\section{Conclusions}

The aim of our Lagrangian process attribution procedure is to provide a framework for interpreting the isotopic composition of tropospheric moisture in a chosen target region by means of individual moisture pathways. In this procedure, we trace the evolution of paired distributions of $\mathrm{H}_{2} \mathrm{O}$ and $\delta \mathrm{D}_{v}$ along backward trajectories. Analyzing the two-dimensional $\left\{\mathrm{H}_{2} \mathrm{O}, \delta \mathrm{D}_{v}\right\}$ phase space, a separation of effects due to mixing and precipitation processes (condensation, evaporation, and equilibration) is possible by following the theoretical process curves of Noone (2012). They usually refer to single processes occurring along idealized air parcel trajectories. However, an application of these curves that explicitly identifies processes occurring along actual trajectories has never been done so far.

As a showcase for our Lagrangian process attribution, we demonstrate how the interpretation of mid-tropospheric $\left\{\mathrm{H}_{2} \mathrm{O}, \delta \mathrm{D}_{v}\right\}$ pair data over the Sahel during the West African Monsoon season 2016 can be improved by considering the past transport pathways and moist processes of inflowing air masses. For this purpose, we use data from a high-resolution, convection-permitting $\mathrm{COSMO}_{\text {iso }}$ simulation and compute Lagrangian backward trajectories started from the Sahelian mid-troposphere. By analyzing the $\left\{\mathrm{H}_{2} \mathrm{O}\right.$, $\left.\delta \mathrm{D}_{v}\right\}$ evolution along individual trajectories as well as clusters of trajectories, we identify characteristic effects of: (1) mixing of moist air masses that were enriched due to surface evaporation and moist advection with subsiding air masses that transport dry and depleted signals from the upper troposphere; (2) condensation associated with convection that follow the Rayleigh model; (3) partial rain evaporation and isotope equilibration of rain drops formed from melting snow that both lead to a depletion of water vapor beyond the Rayleigh prediction, thereby accounting for the so-called SuperRayleigh area. This complements earlier work from Worden et al. (2007) and Risi, Bony, Vimeux, Chongd, and Descroixe (2010), who attributed the enhanced depletion in tropical mid-level water vapor to rain evaporation and dry mixing.

In summary, the combination of the aforementioned processes, which are closely connected with the dominant transport pathways over West Africa, ultimately determine the prevailing signals in $\left\{\mathrm{H}_{2} \mathrm{O}, \delta \mathrm{D}_{v}\right\}$ pairs in the Sahelian mid-troposphere at a given time. 
This kind of Lagrangian process attribution is a valuable foundation for future studies, as it can be flexibly adapted to any region and time period. It holds great potential for an improved interpretation of tropospheric water vapor measurements and for an evaluation of numerical models. While here the analysis has been performed based only on model data, in ongoing studies, the authors examine the potential of comparing the here presented model-based results with remotely sensed Metop/IASI $\left\{\mathrm{H}_{2} \mathrm{O}, \delta \mathrm{D}\right\}$ pair data for the Sahelian troposphere across different time scales. Further, this study lays the meteorological foundation for the development of an improved clustering method that automatically groups trajectories with similar geographical and isotopic properties. As this would require the consideration of multiple dimensions (e.g., three spatial coordinates, time coordinate, $\mathrm{H}_{2} \mathrm{O}$ and $\delta \mathrm{D}$ ), sophisticated clustering algorithms are needed. An approach addressing this challenge is discussed in Ertl et al. (2021) based on the trajectory ensemble from this study. Such an analysis has the potential of generating quantitative information about the occurrence of specific processes along trajectory ensembles and therefore better estimating their impact on $\left\{\mathrm{H}_{2} \mathrm{O}, \delta \mathrm{D}\right\}$ values in specific air masses.

In a long-term perspective, we are confident that careful synergistic analyses combining in-situ and satellite measurements with model simulations and process attribution can improve the general understanding of the hydrological cycle and its representation in weather and climate models.

\section{Appendix A Depletion of $\delta \mathrm{D}_{v}$ due to isotopic equilibration with falling rain}

This appendix provides mathematical evidence that isotopic equilibration between falling rain drops and relatively enriched water vapor in saturated conditions has a depleting effect on $\delta \mathrm{D}_{v}$ in the ambient air.

Following the definitions from Sect. 2, the ratio between the specific water contents of $\mathrm{HDO}$ and $\mathrm{H}_{2} \mathrm{O}$ in rain $(x=r)$ and vapor $(x=v)$ is

$$
R_{x}=\frac{q_{x}^{D}}{q_{x}} ; \quad R_{x, e q}=\frac{q_{x, e q}^{D}}{q_{x, e q}}
$$

with $q_{x}^{D}$ and $q_{x}$ referring to the initial, isotopically non-equilibrated state and $q_{x, e q}^{D}$ and $q_{x, e q}$ denoting the water contents after isotopic equilibration. Analogous to Eqn. 3, the equilibrium fractionation factor for the equilibrated states is

$$
\alpha_{e q}=\frac{R_{r, e q}}{R_{v, e q}}
$$


In saturated conditions there is no net exchange of $\mathrm{H}_{2} \mathrm{O}$ between the rain drop and the ambient water vapor, i.e. $q_{x}=q_{x, e q}$. However, as saturation does not imply automatically that also HDO is in equilibrium, an isotopic flux may be enforced between the rain drop and the vapor that fulfills following criterion:

$$
q_{r}^{D}+q_{v}^{D}=q_{r, e q}^{D}+q_{v, e q}^{D}
$$

Combining Eqn. (A1)-(A3) yields

$$
\begin{aligned}
R_{v, e q}=\frac{1}{\alpha_{e q}} R_{r, e q} & =\frac{1}{\alpha_{e q} q_{r}}\left(q_{r}^{D}+q_{v}^{D}-q_{v, e q}^{D}\right) \\
& =\frac{1}{\alpha_{e q}}\left(R_{r}+\frac{q_{v}}{q_{r}}\left(R_{v}-R_{v, e q}\right)\right)
\end{aligned}
$$

and after further rewriting this results in the following expression:

$$
\frac{R_{v, e q}}{R_{v}}=\frac{\frac{R_{r}}{R_{v}}+\frac{q_{v}}{q_{r}}}{\alpha_{e q}+\frac{q_{v}}{q_{r}}}
$$

Eqn. (A6) relates the ratio of the isotopic composition in the vapor between the equilibrated $\left(R_{v, e q}\right)$ and non-equilibrated $\left(R_{v}\right)$ state to the ratio of the initial, non-equilibrated isotopic compositions of the falling rain $\operatorname{drop}\left(R_{r}\right)$ and the vapor $\left(R_{v}\right)$. As the rain drops form typically further aloft from more depleted vapor, $R_{r}$ is in this case lower than $R_{r, e q}$. Therefore, we can assume that the ratio of $R_{r}$ and $R_{v}$ is lower than $\alpha_{e q}$, such that Eqn. (A6) results in

$$
\frac{R_{v, e q}}{R_{v}}<1
$$

That is, the vapor in equilibrium with the more depleted rain drop is more depleted in $\delta \mathrm{D}_{v}$ than the non-equilibrated vapor. This shows that isotopic equilibration can account for an enhanced depletion in $\delta \mathrm{D}_{v}$, while $\mathrm{H}_{2} \mathrm{O}$ remains unaffected.

\section{Acknowledgments}

The authors acknowledge M. Werner for providing the ECHAM $5_{\text {wiso }}$ data for running the $\mathrm{COSMO}_{\text {iso }}$ model and M. Sprenger for his support with LAGRANTO. This study has been conducted in the context of the project MOTIV (funded by the Deutsche Forschungsgemeinschaft (DFG) under project ID/Geschaeftszeichen 290612604/GZ:SCHN1126/21 and the Swiss National Science Foundation (SNSF, Grant Nr. 164721)) with additional support from the projects TEDDY (DFG, 416767181/GZ:SCHN1126/5-1) and Sentinel$5 \mathrm{P}+$ Innovation - Water Vapour Isotopologogues (H2O-ISO, funded by the European Space Agency). The authors acknowledge the support from the PIRE funding scheme 
via the SNSF Grant Nr. 177996. Simulations were conducted at the Swiss National Supercomputing Centre (CSCS) and the supercomputer ForHLR funded by the Ministry of Science, Research and the Arts Baden-Wuerttemberg and by the German Federal Ministry of Education and Research. The trajectory and model data are available upon request.

\section{References}

Aemisegger, F., Spiegel, J. K., Pfahl, S., Sodemann, H., Eugster, W., \& Wernli, H. (2015). Isotope meteorology of cold front passages: A case study combining observations and modeling. Geophysical Research Letters, 42(13), 5652-5660. doi: 10.1002/2015GL063988

Berthou, S., Rowell, D. P., Kendon, E. J., Roberts, M. J., Stratton, R. A., Crook, J. A., \& Wilcox, C. (2019). Improved climatological precipitation characteristics over West Africa at convection-permitting scales. Climate Dynamics, 53(3-4), 1991-2011. doi: 10.1007/s00382-019-04759-4

Bielli, S., Douville, H., \& Pohl, B. (2010). Understanding the West African monsoon variability and its remote effects: An illustration of the grid point nudging methodology. $\quad$ Climate Dynamics, 35(1), 159-174. doi: $10.1007 / \mathrm{s} 00382-009-0667-8$

Bigeleisen, J. (1961). Statistical Mechanics of Isotope Effects on the Thermodynamic Properties of Condensed Systems. The Journal of Chemical Physics, 34(5), 1485-1493. doi: 10.1063/1.1701033

Bolot, M., Legras, B., \& Moyer, E. J. (2013). Modelling and interpreting the isotopic composition of water vapour in convective updrafts. Atmospheric Chemistry and Physics. doi: 10.5194/acp-13-7903-2013

Bony, S., Risi, C., \& Vimeux, F. (2008). Influence of convective processes on the isotopic composition $(\delta 18 \mathrm{O}$ and $\delta \mathrm{D})$ of precipitation and water vapor in the tropics: 1. Radiative-convective equilibrium and Tropical OceanGlobal Atmosphere-Coupled Ocean-Atmosphere Response Experiment (. Journal of Geophysical Research Atmospheres, 113(19), 1-21. doi: 10.1029/2008JD009942

Celle-Jeanton, H., Gonfiantini, R., Travi, Y., \& Sol, B. ～(2004). Oxygen-18 variations of rainwater during precipitation: Application of the Rayleigh model to 
selected rainfalls in Southern France. Journal of Hydrology, 289(1-4), 165-177. doi: 10.1016/j.jhydrol.2003.11.017

Christner, E., Aemisegger, F., Pfahl, S., Werner, M., Cauquoin, A., Schneider, M., ... Schädler, G. (2018). The Climatological Impacts of Continental Surface Evaporation, Rainout, and Subcloud Processes on $\delta \mathrm{D}$ of Water Vapor and Precipitation in Europe. Journal of Geophysical Research: Atmospheres, 123(8), 4390-4409. doi: 10.1002/2017JD027260

Ciais, P., \& Jouzel, J. (1994). Deuterium and oxygen 18 in precipitation: isotopic model, including mixed cloud processes. Journal of Geophysical Research, 99(D8). doi: 10.1029/94jd00412

Cook, K. H. (1999). Generation of the African easterly jet and its role in determining West African precipitation. Journal of Climate, 12(5 I), 1165-1184. doi: 10 .1175/1520-0442(1999)012〈1165:GOTAEJ $\rangle 2.0 . C O ; 2$

Craig, H. (1961). Standard for reporting concentrations of deuterium and oxygen18 in natural waters. Science, 133(3467), 1833-1834. doi: 10.1126/science.133 .3467 .1833

Craig, H., \& Gordon, L. (1965). Deuterium and oxygen-18 variations in the ocean and the marine atmosphere. $\quad E$. Tongiorgi (Ed.), Stable Isotopes in Oceanographic Studies and Paleotemperatures,(Cons. Naz. Ric., Lab. Geol. Nucl, Pisa), 9-72.

Crook, J., Klein, C., Folwell, S., Taylor, C. M., Parker, D. J., Stratton, R., \& Stein, T. (2019). Assessment of the Representation of West African Storm Lifecycles in Convection-Permitting Simulations. Earth and Space Science, 6(5), 818-835. doi: 10.1029/2018EA000491

Dansgaard, W. (1964). Stable isotopes in precipitation. Tellus, 16(4), 436-468. doi: 10.1111/j.2153-3490.1964.tb00181.x

Diekmann, C. J., Schneider, M., Ertl, B., Hase, F., García, O. E., Khosrawi, F., ... Braesicke, P. (2021). The MUSICA IASI $\{\mathrm{H} 2 \mathrm{O}, \delta \mathrm{D}\}$ pair product. submitted to Earth System Science Data.

Dütsch, M., Pfahl, S., Meyer, M., \& Wernli, H. (2018). Lagrangian process attribution of isotopic variations in near-surface water vapour in a 30-year regional climate simulation over Europe. Atmospheric Chemistry and Physics, 18(3), 1653-1669. doi: 10.5194/acp-18-1653-2018 
Eckstein, J., Ruhnke, R., Pfahl, S., Christner, E., Diekmann, C., Dyroff, C., ... Braesicke, P. (2018). From climatological to small-scale applications: Simulating water isotopologues with ICON-ART-Iso (version 2.3). Geoscientific Model Development, 11(12), 5113-5133. doi: 10.5194/gmd-11-5113-2018

Ertl, B., Meyer, J., Schneider, M., Diekmann, C. J., \& Streit, A. (2021). A SemiSupervised Approach for Trajectory Segmentation to Identify Different Processes in the Atmosphere. subm. to International Conference on Computational Science.

Field, R. D., Jones, D. B., \& Brown, D. P. $\quad$ (2010). Effects of postcondensation exchange on the isotopic composition of water in the atmosphere. Journal of Geophysical Research Atmospheres, 115(24). doi: 10.1029/2010JD014334

Fink, A. H., Engel, T., Ermert, V., Van Der Linden, R., Schneidewind, M., Redl, R., ... Janicot, S. (2017). Mean climate and seasonal cycle. In Meteorology of tropical west africa: The forecasters' handbook (pp. 1-39). Chichester, UK: John Wiley \& Sons, Ltd. doi: 10.1002/9781118391297.ch1

Fink, A. H., \& Reiner, A. (2003). Spatiotemporal variability of the relation between African Easterly Waves and West African Squall Lines in 1998 and 1999. Journal of Geophysical Research: Atmospheres, 108(11). doi: $10.1029 / 2002 j \mathrm{j} 002816$

Fitzpatrick, R. G., Bain, C. L., Knippertz, P., Marsham, J. H., \& Parker, D. J. (2015). The West African monsoon onset: A concise comparison of definitions. Journal of Climate, 28(22), 8673-8694. doi: 10.1175/JCLI-D-15-0265.1

Gedzelman, S. D. (1988). Deuterium in water vapor above the atmospheric boundary layer. Tellus B, 40 B(2), 134-147. doi: 10.1111/j.1600-0889.1988.tb00217 . $\mathrm{x}$

González, Y., Schneider, M., Dyroff, C., Rodríguez, S., Christner, E., García, O. E., ... Sepúlveda, E. (2016). Detecting moisture transport pathways to the subtropical North Atlantic free troposphere using paired H2O- $\delta \mathrm{D}$ in situ measurements. Atmospheric Chemistry and Physics, 16(7), 4251-4269. doi: 10.5194/acp-16-4251-2016

Graf, P., Wernli, H., Pfahl, S., \& Sodemann, H. ～(2019). A new interpretative framework for below-cloud effects on stable water isotopes in vapour and rain. Atmospheric Chemistry and Physics, 19(2), 747-765. doi: 
Hall, N. M., \& Peyrillé, P. (2006). Dynamics of the West African monsoon. In Journal de physique. iv : Jp (Vol. 139, pp. 81-99). EDP Sciences. doi: 10.1051/jp4: 2006139007

Horita, J., \& Wesolowski, D. J. ～(1994). Liquid-vapor fractionation of oxygen and hydrogen isotopes of water from the freezing to the critical temperature. Geochimica et Cosmochimica Acta, 58(16), 3425-3437. doi: 10.1016/0016-7037(94)90096-5

Johnson, D. G., Jucks, K. W., Traub, W. A., \& Chance, K. V. $\quad$ (2001). $\quad$ Isotopic composition of stratospheric water vapor: Implications for transport. Journal of Geophysical Research Atmospheres, 106 (D11), 12219-12226. doi: 10.1029/ 2000JD900764

Jouzel, J., \& Merlivat, L. (1984). Deuterium and oxygen 18 in precipitation: Modeling of the isotopic effects during snow formation. Journal of Geophysical Research, 89(D7), 11749. doi: 10.1029/JD089iD07p11749

Keeling, C. D. (1958). The concentration and isotopic abundances of atmospheric carbon dioxide in rural areas. Geochimica et Cosmochimica Acta, 13(4), 322334. doi: 10.1016/0016-7037(58)90033-4

Knippertz, P., Fink, A. H., Deroubaix, A., Morris, E., Tocquer, F., Evans, M. J., ... Schlueter, A. (2017). A meteorological and chemical overview of the DACCIWA field campaign in West Africa in June-July 2016. Atmospheric Chemistry and Physics, 17(17), 10893-10918. doi: 10.5194/acp-17-10893-2017

Kurita, N. (2013). Water isotopic variability in response to mesoscale convective system over the tropical ocean. Journal of Geophysical Research Atmospheres, 118 (18), 10,376-10,390. doi: 10.1002/jgrd.50754

Lacour, J. L., Flamant, C., Risi, C., Clerbaux, C., \& Coheur, P. F. (2017). Importance of the Saharan heat low in controlling the North Atlantic free tropospheric humidity budget deduced from IASI $\delta$ d observations. Atmospheric Chemistry and Physics, 17(15), 9645-9663. doi: 10.5194/acp-17-9645-2017

Lacour, J. L., Risi, C., Worden, J., Clerbaux, C., \& Coheur, P. F. (2018). Importance of depth and intensity of convection on the isotopic composition of water vapor as seen from IASI and TES $\delta \mathrm{D}$ observations. Earth and Planetary Science Letters, 481, 387-394. doi: 10.1016/j.epsl.2017.10.048 
Lavaysse, C., Flamant, C., Janicot, S., Parker, D. J., Lafore, J. P., Sultan, B., \& Pelon, J. (2009). Seasonal evolution of the West African heat low: A climatological perspective. Climate Dynamics, 33(2-3), 313-330. doi: $10.1007 / \mathrm{s} 00382-009-0553-4$

Lawrence, J. R., Gedzelman, S. D., Dexheimer, D., Cho, H. K., Carrie, G. D., Gasparini, R., ... Biggerstaff, M. I. (2004). Stable isotopic composition of water vapor in the tropics. Journal of Geophysical Research: Atmospheres, 109(6). doi: $10.1029 / 2003 j \mathrm{~d} 004046$

Lee, J. E., \& Fung, I. (2008). "Amount effect" of water isotopes and quantitative analysis of post-condensation processes. Hydrological Processes, 22(1), 18. doi: 10.1002/hyp.6637

Majoube, M. (1971). Fractionnement en oxygène 18 et en deutérium entre l'eau et sa vapeur. Journal de Chimie Physique, 68, 1423-1436. doi: 10.1051/jcp/ 1971681423

Maranan, M., Fink, A. H., Knippertz, P., Francis, S. D., Akpo, A. B., Jegede, G., \& Yorke, C. (2019). Interactions between convection and a moist vortex associated with an extreme rainfall event over southern West Africa. Monthly Weather Review, 147(7), 2309-2328. doi: 10.1175/MWR-D-18-0396.1

Marsham, J. H., Dixon, N. S., Garcia-Carreras, L., Lister, G. M., Parker, D. J., Knippertz, P., \& Birch, C. E. (2013). The role of moist convection in the West African monsoon system: Insights from continental-scale convectionpermitting simulations. Geophysical Research Letters, 40(9), 1843-1849. doi: $10.1002 / \operatorname{grl} .50347$

Martínez, I. R., \& Chaboureau, J. P. (2018). Precipitation and Mesoscale convective systems: Explicit versus parameterized convection over Northern Africa. Monthly Weather Review, 146(3), 797-812. doi: 10.1175/MWR-D-17-0202.1

Maurer, V., Bischoff-Gauß, I., Kalthoff, N., Gantner, L., Roca, R., \& Panitz, H. J. (2017). Initiation of deep convection in the Sahel in a convection-permitting climate simulation for northern Africa. Quarterly Journal of the Royal Meteorological Society, 143(703), 806-816. doi: 10.1002/qj.2966

Merlivat, L., \& Jouzel, J. (1979). Global climatic interpretation of the deuteriumoxygen 18 relationship for precipitation. Journal of Geophysical Research, 84(C8), 5029. doi: 10.1029/JC084iC08p05029 
Merlivat, L., \& Nief, G. (1967). Fractionnement isotopique lors des changements d'état solide-vapeur et liquide-vapeur de l'eau à des températures inférieures à $0^{\circ} \mathrm{C}$. Tellus, $19(1), 122-127$. doi: 10.1111/j.2153-3490.1967.tb01465.x

Meynadier, R., Bock, O., Gervois, S., Guichard, F., Redelsperger, J. L., AgustPanareda, A., \& Beljaars, A. (2010). West African Monsoon water cycle: 2. Assessment of numerical weather prediction water budgets. Journal of Geophysical Research Atmospheres, 115(19), D19107. doi: 10.1029/ 2010JD013919

Meynadier, R., Bock, O., Guichard, F., Boone, A., Roucou, P., \& Redelsperger, J. L. (2010). West African Monsoon water cycle: 1. A hybrid water budget data set. Journal of Geophysical Research Atmospheres, 115(19), D19106. doi: 10.1029/2010JD013917

Niang, C., Mancho, A. M., García-Garrido, V. J., Mohino, E., Rodriguez-Fonseca, B., \& Curbelo, J. (2020). Transport pathways across the West African Monsoon as revealed by Lagrangian Coherent Structures. Scientific Reports, 10(1). doi: 10.1038/s41598-020-69159-9

Nieto, R., Gimeno, L., \& Trigo, R. M. (2006). A Lagrangian identification of major sources of Sahel moisture. Geophysical Research Letters, 33(18), L18707. doi: 10.1029/2006GL027232

Noone, D. (2012). Pairing measurements of the water vapor isotope ratio with humidity to deduce atmospheric moistening and dehydration in the tropical midtroposphere. Journal of Climate, 25(13), 4476-4494. doi: 10.1175/JCLI-D-11-00582.1

Noone, D., Galewsky, J., Sharp, Z. D., Worden, J., Barnes, J., Baer, D., ... Wright, J. S. (2011). Properties of air mass mixing and humidity in the subtropics from measurements of the $\mathrm{D} / \mathrm{H}$ isotope ratio of water vapor at the Mauna Loa Observatory. Journal of Geophysical Research Atmospheres, 116(22). doi: 10.1029/2011JD015773

Pante, G., \& Knippertz, P. (2019). Resolving Sahelian thunderstorms improves midlatitude weather forecasts. Nature Communications, 10(1), 1-9. doi: 10.1038/ s41467-019-11081-4

Parker, D. J., Fink, A., Janicot, S., Ngamini, J. B., Douglas, M., Afiesimama, E., ... Wilson, G. A. (2008). The Amma radiosonde program and its implications 
for the future of atmospheric monitoring over Africa. Bulletin of the American Meteorological Society, 89(7), 1015-1027. doi: 10.1175/2008BAMS2436.1

Pfahl, S., Wernli, H., \& Yoshimura, K. (2012). The isotopic composition of precipitation from a winter storm-a case study with the limited-area model COSMOiso. Atmospheric Chemistry and Physics, 12(3), 1629-1648. doi: 10.5194/acp-12-1629-2012

Rayleigh, L. (1902). On the distillation of binary mixtures. The London, Edinburgh, and Dublin Philosophical Magazine and Journal of Science, 4(23), 521-537. doi: 10.1080/14786440209462876

Risi, C., Bony, S., \& Vimeux, F. (2008). Influence of convective processes on the isotopic composition $(\delta 18 \mathrm{O}$ and $\delta \mathrm{D})$ of precipitation and water vapor in the tropics: 2. Physical interpretation of the amount effect. Journal of Geophysical Research Atmospheres, 113(19). doi: 10.1029/2008JD009943

Risi, C., Bony, S., Vimeux, F., Chongd, M., \& Descroixe, L. (2010). Evolution of the stable water isotopic composition of the rain sampled along sahelian squall lines. Quarterly Journal of the Royal Meteorological Society, 136(SUPPL. 1), 227-242. doi: 10.1002/qj.485

Risi, C., Bony, S., Vimeux, F., Descroix, L., Ibrahim, B., Lebreton, E., ... Sultan, B. (2008). What controls the isotopic composition of the African monsoon precipitation? Insights from event-based precipitation collected during the 2006 AMMA field campaign. Geophysical Research Letters, 35(24), 1-6. doi: 10.1029/2008GL035920

Risi, C., Bony, S., Vimeux, F., Frankenberg, C., Noone, D., \& Worden, J. (2010). Understanding the Sahelian water budget through the isotopic composition of water vapor and precipitation. Journal of Geophysical Research Atmospheres, 115(24), 1-23. doi: 10.1029/2010JD014690

Roca, R., Lafore, J. P., Piriou, C., \& Redelsperger, J. L. (2005). Extratropical dryair intrusions into the West African monsoon midtroposphere: An important factor for the convective activity over the Sahel. Journal of the Atmospheric Sciences, 62(2), 390-407. doi: 10.1175/JAS-3366.1

Roehrig, R., Bouniol, D., Guichard, F., Hourdin, F., \& Redelsperger, J. L. The present and future of the west african monsoon: A process-oriented assessment of CMIP5 simulations along the AMMA transect. Journal of Climate, 
26 (17), 6471-6505. doi: 10.1175/JCLI-D-12-00505.1

Rozanski, K., Araguãs-Araguãs, L., \& Gonfiantini, R. (1992). Relation between long-term trends of oxygen-18 isotope composition of precipitation and climate. Science, 258(5084), 981-985. doi: 10.1126/science.258.5084.981

Salih, A. A., Zhang, Q., \& Tjernström, M. (2015). Lagrangian tracing of Sahelian Sudan moisture sources. Journal of Geophysical Research, 120(14), 6793-6808. doi: 10.1002/2015JD023238

Schneider, M., Ertl, B., Khosrawi, F., Weber, A., Hase, F., Garcia, O. E., ... Kinnison, D. (2021). MUSICA IASI data: full retrieval product. currently in preparation for Earth System Science Data.

Schneider, M., Wiegele, A., Barthlott, S., González, Y., Christner, E., Dyroff, C., ... Andrey, J. (2016). Accomplishments of the MUSICA project to provide accurate, long-term, global and high-resolution observations of tropospheric $\{\mathrm{H} 2 \mathrm{O}, \delta \mathrm{D}\}$ pairs - A review. $\quad$ Atmospheric Measurement Techniques, $9(7)$, 2845-2875. doi: 10.5194/amt-9-2845-2016

Sodemann, H. (2020). Beyond turnover time: Constraining the lifetime distribution of water vapor from simple and complex approaches. Journal of the Atmospheric Sciences, 77(2), 413-433. doi: 10.1175/JAS-D-18-0336.1

Sodemann, H., Schwierz, C., \& Wernli, H. (2008). Interannual variability of Greenland winter precipitation sources: Lagrangian moisture diagnostic and North Atlantic Oscillation influence. Journal of Geophysical Research Atmospheres, 113(3). doi: 10.1029/2007JD008503

Sprenger, M., \& Wernli, H. (2015). The LAGRANTO Lagrangian analysis tool Version 2.0. Geoscientific Model Development, 8(8), 2569-2586. doi: 10.5194/ gmd-8-2569-2015

Steppeler, J., Doms, G., Schattler, U., Bitzer, H. W., Gassmann, A., Damrath, U., \& Gregoric, G. (2003). Meso-gamma scale forecasts using the nonhydrostatic model LM. Meteorology and Atmospheric Physics, 82(1-4), 75-96. doi: 10.1007/s00703-001-0592-9

Stewart, M. K. (1975). Stable isotope fractionation due to evaporation and isotopic exchange of falling waterdrops: Applications to atmospheric processes and evaporation of lakes. Journal of Geophysical Research, $80(9), 1133 . \quad$ doi: 10.1029/JC080i009p01133 
Sultan, B., \& Janicot, S. (2003). The West African monsoon dynamics. Part II: The "preonset" and "onset" of the summer monsoon. Journal of Climate, 16(21), 3407-3427. doi: 10.1175/1520-0442(2003)016〈3407:TWAMDP $>2.0 . C O ; 2$

Sy, A., Diop, B., Van Baelen, J., Duroure, C., Gour, Y., \& Baray, J. L. (2018). Upper troposphericwater vapor transport from Indian to Sahelian Regions. Atmosphere, $9(10)$, 403. doi: 10.3390/atmos9100403

Tremoy, G., Vimeux, F., Mayaki, S., Souley, I., Cattani, O., Risi, C., ... Oi, M.

(2012). A 1-year long $\delta 180$ record of water vapor in Niamey (Niger) reveals insightful atmospheric processes at different timescales. Geophysical Research Letters, 39(8). doi: 10.1029/2012GL051298

Tremoy, G., Vimeux, F., Soumana, S., Souley, I., Risi, C., Favreau, G., \& Ö̈, M. (2014). Clustering mesoscale convective systems with laser-based water vapor $\delta 18 \mathrm{O}$ monitoring in niamey (Niger). Journal of Geophysical Research, 119(9), 5079-5103. doi: 10.1002/2013JD020968

Tyrlis, E., \& Lelieveld, J. (2013). Climatology and dynamics of the summer Etesian winds over the eastern Mediterranean. Journal of the Atmospheric Sciences, 70 (11), 3374-3396. doi: 10.1175/JAS-D-13-035.1

Urey, H. C. (1947). The thermodynamic properties of isotopic substances. Liversidge lecture, delivered before the Chemical Society in the Royal Institution on December 18th, 1946. Journal of the Chemical Society (Resumed), 562-581. doi: $10.1039 / \mathrm{jr} 9470000562$

Vergara-Temprado, J., Ban, N., Panosetti, D., Schlemmer, L., \& Schär, C. (2020). Climate models permit convection at much coarser resolutions than previously considered. Journal of Climate, 33(5), 1915-1933. doi: 10.1175/JCLI-D-19-0286.1

Vogel, P., Knippertz, P., Fink, A. H., Schlueter, A., \& Gneiting, T. Skill of global raw and postprocessed ensemble predictions of rainfall over Northern Tropical Africa. Weather and Forecasting, 33(2), 369-388. doi: 10.1175/WAF-D-17-0127.1

Werner, M., Langebroek, P. M., Carlsen, T., Herold, M., \& Lohmann, G. (2011). Stable water isotopes in the ECHAM5 general circulation model: Toward highresolution isotope modeling on a global scale. Journal of Geophysical Research, 116(D15), D15109. doi: 10.1029/2011JD015681 
Wernli, H., \& Davies, H. C. (1997). A Lagrangian-based analysis of extratropical cyclones. I: The method and some applications. Quarterly Journal of the Royal Meteorological Society, 123(538), 467-489. doi: 10.1002/qj.49712353811

Worden, J., Noone, D., Bowman, K., Beer, R., Eldering, A., Fisher, B., ... Worden, H. (2007). Importance of rain evaporation and continental convection in the tropical water cycle. Nature, 445(7127), 528-532. doi: 10.1038/nature05508

Wu, M. L. C., Reale, O., Schubert, S. D., Suarez, M. J., Koster, R. D., \& Pegion, P. J. (2009). African easterly jet: Structure and maintenance. Journal of Climate, 22(17), 4459-4480. doi: 10.1175/2009JCLI2584.1

Yang, H., \& Pierrehumbert, R. T. (1994). Production of dry air by isentropic mixing. Journal of the Atmospheric Sciences, 51(23), 3437-3454. doi: 10.1175/ 1520-0469(1994)051〈3437:PODABI〉2.0.CO;2 